\title{
Somatic growth dilution of a toxicant in a predator-prey model under stoichiometric constraints
}

\author{
Angela Peace ${ }^{1 \mathrm{a}, \mathrm{b}}$, Monica D. Poteat ${ }^{\mathrm{c}}$, Hao Wang ${ }^{\mathrm{d}}$ \\ ${ }^{a}$ Department of Mathematics and Statistics, Texas Tech University, Lubbock, USA \\ ${ }^{b}$ National Institute for Mathematical and Biological Synthesis, University of Tennessee, U.S.A. \\ ${ }^{c}$ Environmental Sciences Division, Oak Ridge National Laboratory, Oak Ridge, TN, USA \\ ${ }^{d}$ Centre for Mathematical Biology, Department of Mathematical and Statistical Sciences, University of Alberta, \\ Edmonton, AB, T6G 2G1, Canada
}

\begin{abstract}
The development of aquatic food chain models that incorporate both the effects of nutrient availability, as well as, track toxicants through trophic levels will shed light on ecotoxicological processes and ultimately help improve risk assessment efforts. Here we develop a stoichiometric aquatic food chain model of two trophic levels that investigates concurrent nutrient and toxic stressors in order to improve our understanding of the processes governing the trophic transfer for nutrients, energy, and toxicants. Analytical analysis of positive invariance, local stability of boundary equilibria, numerical simulations, and bifurcation analysis are presented. The model captures and explores a phenomenon called the Somatic Growth Dilution (SGD) effect recently observed empirically, where organisms experience a greater than proportional gain in biomass relative to toxicant concentrations when consuming food with high nutritional content vs. low quality food.
\end{abstract}

Keywords: methylmercury, predator-prey model, ecological stoichiometry, ecotoxicology

\section{Introduction}

Chemical contaminants are widely dispersed throughout Earth's ecosystems due to a multitude of human activities, as well as natural phenomena, and have the potential to adversely impact a diverse range of organisms (Walker et al, 2012). Bioaccumulation of toxic compounds in aquatic food chains can pose risk to ecosystem conservation as well as wildlife and human health. Accurately assessing the risks of contaminants requires more than an understanding of the effects of contaminants on individual organisms, but requires further understandings of complex ecological interactions, elemental cycling, and the interactive effects of natural stressors, such as resource limitations, and contaminant stressors.

Ecotoxicological modeling aims to predict how contaminants cycle through aquatic food systems. It is vital to understand the processes that determine the trophic transfer of toxicants to improve developed risk assessment protocols. Wang et al (1996) developed a simple biokinetic model that has been used to predict total bioaccumulated toxicant concentrations in multiple species of aquatic organisms over that last decade (Wang and Rainbow, 2008; Wang, 2012). It models the change in toxicant concentration $(v)$ in an organism due to uptake and loss due to efflux and growth:

\footnotetext{
${ }^{1}$ corresponding author at: Tel: +1 806834 1014; E-mail address: a.peace@ttu.edu
} 


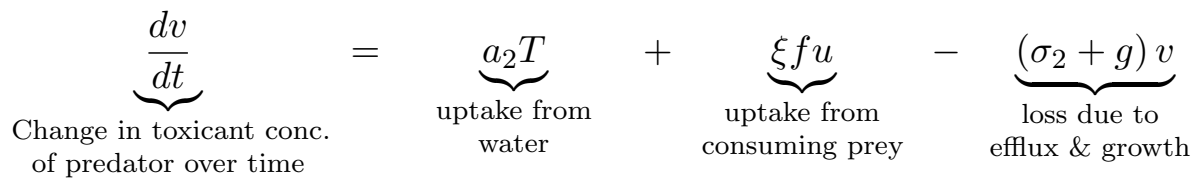

where $a_{2}$ is the uptake rate constant from the dissolved toxicant, $T$ is the concentration of dissolved toxicant, $\xi$ is the toxicant assimilation efficiency, $f$ is the predator's ingestion rate, $u$ is the toxicant concentration in the prey, $\sigma_{2}$ is the toxicant efflux rate, and $g$ is the predator's growth rate. The Biokinetic model (1) incorporates constant parameters for the predator's growth rate $(g)$ and ingestion rate $(f)$. It also assumes the quantity and toxicant concentration in the prey are constant.

Dynamic ecological population models can offer insight on the variability of these biokinetic parameters and their influences on the trophic transfer of toxicants. Huang et al (2014) developed a toxicant-mediated predator-prey model that incorporates a variable prey quantity. This model tracks the prey and predator population densities, as well as the toxicant body burdens in each population. The biokinetic model (1) corresponds with the predator body burden equation from Huang et al (2014) :

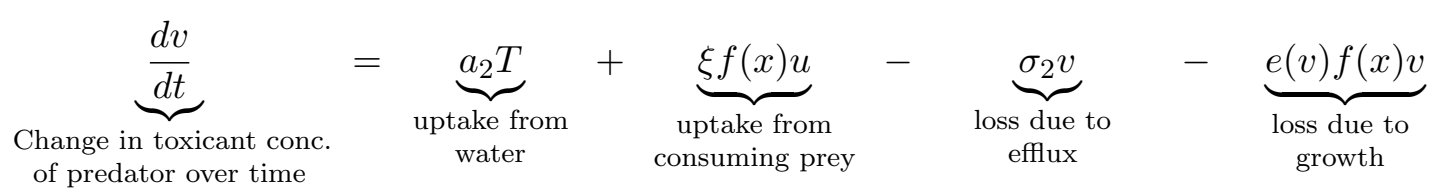

where $e(v)$ is the toxicant dependent biomass conversion efficiency. The original constant ingestion rate $f$ is replaced with function $f(x)$ and depends on prey quantity; the constant predator growth rate $g$ is replaced with the expression $e(v) f(x)$ and depends on the prey quantity, as well as, the predator's toxicant concentration. Huang et al (2014) parameterize their model with the toxicant mercury $(\mathrm{Hg})$, a toxic contaminant that can bioaccumulate in aquatic food chains as methylmercury $(\mathrm{MeHg})$ posing risk to ecosystems and humans (Mergler et al, 2007). Their toxicant-mediated predator-prey model helped shed light on the different complicated ways varying toxicant concentrations affects organisms at different trophic levels.

While this model incorporates variable food quantity, it does not consider food quality. Elemental imbalances, such as phosphorus:carbon (P:C) ratios, between trophic levels affect life-history traits such as growth and reproduction. Toxic compounds can have similar impacts on these traits. There is increasing evidence that considering resource stoichiometry and nutrient availability will improve risk assessment protocols in ecotoxicology (Ieromina et al, 2014; Sarwar et al, 2010; Lessard and Frost, 2012; Alexander et al, 2013). The interactive effects of nutrient availability and aqueous $\mathrm{Hg}$ concentration may play a significant role in the bioaccumulation of MeHg. Karimi et al (2007) shows stoichiometric constraints, such as food quality, can affect the accumulation of $\mathrm{MeHg}$ in Daphnia. They show empirical evidence of Somatic Growth Dilution (SGD) as Daphnia experience a greater than proportional gain in biomass relative to $\mathrm{MeHg}$ under high phosphorus concentrations (Figure 1). They used MeHg radio-tracer to measure juvenile Daphnia pulex $\mathrm{MeHg}$ concentrations, growth rate, and ingestion rate when fed on $A$. falcatus algae of low and high quality (vary algal P:C ratio). Estimated Daphnia steady-state $\mathrm{MeHg}$ concentrations using the biokinetic model (System (1)) showed that Daphnia grown on high quality food had 3.5 times higher growth rates, slightly lower ingestion rates, and $\mathrm{MeHg}$ concentrations at steady-state a third lower than Daphnia grown on low quality food. 


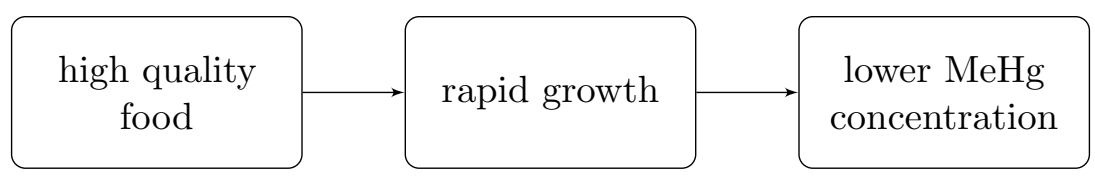

Figure 1: Simple depiction of Somatic Growth Dilution (SGD), where an organism experiences a greater than proportional gain in biomass relative to toxicant under high food quality conditions.

Given this empirical evidence, the interactive effects of resource limitation and contaminant stress on organisms and ecosystems needs to be considered in toxicological risk assessment applications. Models have proven to be useful tools in ecotoxicological predictions, however current models do not consider dynamical interactive effects of contaminant stressors and stoichiometric constraints, such as nutrient/light availability and food quality.

In order to incorporate and balance multiple essential elements and contaminants, the mathematical models and the empirical experiments will be structured under the framework of the theory of Ecological Stoichiometry (Sterner and Elser, 2002). This theory considers the balance of multiple chemical elements and how the relative abundance of essential elements, such as carbon (C), nitrogen $(\mathrm{N})$, and phosphorus $(\mathrm{P})$, in organisms affects ecological dynamics. Ecologists have made important progress collecting large amounts of data from both lab experiments and field sites to support Ecological Stoichiometry (Andersen (1997); Sterner and Elser (2002); Urabe and Sterner (1996); Elser et al (1996); Elser and Urabe (1999); Elser et al (2000, 2001); Urabe et al (2002); McCauley et al (2008); Hessen et al (2013)). Since the development of the theory of ecological stoichiometry, a wide variety of stoichiometric food web models have been proposed and analyzed (Andersen, 1997; Loladze et al, 2000; Grover, 2004; Hall, 2004; Wang et al, 2008a; Hall, 2009; Wang et al, 2012; Peace et al, 2013, 2014). Stoichiometric models incorporate the effects of both food quantity and food quality into a single framework that produces rich dynamics. Stoichiometric models allow one to investigate the effects of nutrient stressors on population dynamics and track the trophic transfer of energy and nutrients (Peace, 2015). Empirical efforts and models developed under the theory of Ecological Stoichiometry have advanced our understanding of ecological interactions (Andersen et al, 2004; Hessen et al, 2013).

Two existing ecotoxicology models do consider a contaminant stressor along with a single stoichiometric constraint: 1.) Bontje et al (2009) developed a model that considers both nutrient stress and toxicant stress parameterized for a N-limited algal population and 2.) Ankley et al (1995) developed a model that considers both light availabilities and contaminant concentrations to looks at the effects of varying light intensities on a photo-activated contaminant stressor on aquatic organisms. However, unlike Ecological Stoichiometric models, these model do not allow for multiple dynamic stoichiometric constraints where the element limiting growth can change with environmental nutrient and light availabilities.

Ecological Stoichiometry has proven successful in aquatic ecological applications and has the potential to improve our understanding of the effects chemical contaminants have on organisms and ecosystems (Hansen et al, 2008). It offers a conceptual framework to investigate the impact of elemental imbalances on the response of organisms to contaminants while simultaneously considering the effects of contaminants on ecosystem processes (Danger and Maunoury-Danger, 2013).

Here, we extend System (3) under the framework of Ecological Stoichiometry (Sterner and Elser, 2002) to develop a toxicant-mediated predator-prey model that incorporates a variable food quantity as well as quality. Loladze et al (2000) formulated a stoichiometric predator-prey Lotka-Volterra type model (LKE model) of the first two trophic levels of an aquatic food chain incorporating the fact that both the predator and prey are chemically heterogeneous organisms composed of two 
essential elements, carbon $(\mathrm{C})$ and phosphorus $(\mathrm{P})$. The model allows the phosphorus to carbon ratio $(\mathrm{P}: \mathrm{C})$ of the prey to vary above a minimum value, which brings food quality into the model. The LKE model is described in detail in Appendix A and is used as guide as we expand System 3 under the Ecological Stoichiometric framework. These modeling efforts help shed light on nutrient and chemical contaminant cycling and ultimately can improve toxicological risk assessment protocols.

\section{Model formulation}

We start with the toxicant-mediated predator-prey model developed by Huang et al (2014):

$$
\begin{aligned}
& \underbrace{\frac{d x}{d t}}_{\begin{array}{c}
\text { Change in prey } \\
\text { density over time }
\end{array}}=\underbrace{b(u, x) x}_{\begin{array}{c}
\text { gain from } \\
\text { growth }
\end{array}}-\underbrace{d_{1}(u) x}_{\begin{array}{c}
\text { loss from } \\
\text { death }
\end{array}}-\underbrace{f(x) y}_{\begin{array}{c}
\text { loss from } \\
\text { predation }
\end{array}} \\
& \underbrace{\frac{d y}{d t}}_{\begin{array}{c}
\text { Change in predator } \\
\text { density over time }
\end{array}}=\underbrace{e(v) f(x) y}_{\begin{array}{c}
\text { gain from } \\
\text { growth }
\end{array}}-\underbrace{d_{2}(v) y}_{\begin{array}{c}
\text { loss from } \\
\text { death }
\end{array}} \\
& \underbrace{\frac{d u}{d t}}_{\begin{array}{c}
\text { Change in toxicant } \\
\text { in prey over time }
\end{array}}=\underbrace{a_{1} T}_{\begin{array}{c}
\text { uptake from } \\
\text { water }
\end{array}}-\underbrace{\sigma_{1} u}_{\text {efflux }}-\underbrace{b(u, x) u}_{\begin{array}{c}
\text { loss due to } \\
\text { growth }
\end{array}} \\
& \underbrace{\frac{d v}{d t}}_{\begin{array}{c}
\text { Change in toxicant } \\
\text { in predator over time }
\end{array}}=\underbrace{a_{2} T}_{\begin{array}{c}
\text { uptake from } \\
\text { water }
\end{array}}-\underbrace{\sigma_{2} v}_{\text {efflux }}+\underbrace{\xi f(x) u}_{\begin{array}{c}
\text { uptake from } \\
\text { prey }
\end{array}}-\underbrace{e(v) f(x) v}_{\begin{array}{c}
\text { loss due to } \\
\text { growth }
\end{array}}
\end{aligned}
$$

where $x$ and $y$ are the prey and predator population densities $(\mathrm{mg} \mathrm{C} / \mathrm{L})$ respectively and $u$ and $v$ give toxicant body burden, or the concentrations of the toxicant in the prey and predatory, respectively. Function $b(u, x)$ is the toxicant dependent prey growth rate, $d_{1}(u)$ and $d_{2}(v)$ are toxicant dependent death rates for the prey and predator, respectively, $f(x)$ is the predator ingestion rate, $e(v)$ is the toxicant dependent biomass conversion efficiency, $a_{1}, a_{2}$ are toxicant uptake rates and $\sigma_{1}, \sigma_{2}$ are toxicant efflux rates for the prey and predator, respectively, and $\xi$ is the predator toxicant assimilation efficiency.

We extend System (3) under the framework of Ecological Stoichiometry (Sterner and Elser, 2002) to develop a toxicant-mediated predator-prey model that incorporates a variable food quantity as well as quality. First, consider the prey growth rate presented in Huang et al (2014),

$$
b(u, x)=\frac{\alpha_{1} \max \left\{0,1-\alpha_{2} u\right\}}{1+\alpha_{3} x}
$$

where $0 \leq \max \left\{0,1-\alpha_{2} u\right\} \leq 1$ comes from a linear dose response for the gain rate. Parameter $\alpha_{1}$ is the maximum prey growth rate, $\alpha_{2}$ is the effect of the toxicant on the prey growth rate, and $\alpha_{3}$ accounts for the effect of crowding on the prey. Logistic growth is commonly used in the Ecological Stoichiometry framework, as the carrying capacity is easily modified to depend on carbon (light) and $\mathrm{P}$ availability. Here we represent growth with a logistic growth expression where the linear dose response gain rate is incorporated into the maximum growth rate parameter:

$$
b(u, x, y)=\alpha_{1} \max \left\{0,1-\alpha_{2} u\right\}\left(1-\frac{x}{\min \left\{K, \frac{P-\theta y}{q}\right\}}\right)
$$


Here $\alpha_{1}$ is the maximum intrinsic growth rate of the prey and the above logistic growth expression includes any natural morality of the prey, $K$ is the prey carrying capacity in terms of carbon or light availability, $P$ is the total about of phosphorus in the system, $\theta$ is the constant predator $\mathrm{P}: \mathrm{C}$ ratio, $q$ is the minimum $\mathrm{P}: \mathrm{C}$ ratio of the prey, and $\mathrm{Q}$ is the variable prey $\mathrm{P}: \mathrm{C}$ ratio:

$$
Q=\frac{P-\theta y}{x} \text {. }
$$

The above equation is based on the assumption that all available nutrients are either in the prey or the predator. The model does not allow for free nutrients to be in the environment. This assumption is based on the fact that algae take up nutrients very quickly. This is also assumed in Loladze et al (2000). Relaxation of this assumption has been investigated in stoichiometric models that track free nutrients in the environment (Wang et al, 2008a; Peace et al, 2014). A minimum function is used to describe the prey carrying capacity, $\min \{K,(P-\theta y) / q\}$. The first input, $K$, is the carrying capacity determined by light availability. The second input, $(P-\theta y) / q$ is the carrying capacity determined by phosphorus availability.

Now, consider the predator's conversion efficiency presented in Huang et al (2014),

$$
e(v)=\beta_{1} \max \left\{0,1-\beta_{2} v\right\}
$$

where $0<\beta_{1}<1$ is the growth efficiency, and $\max \left\{0,1-\beta_{2} v\right\}$ represents a linear dose response for the growth efficiency where $\beta_{2}$ is the effect of the toxicant on predator growth. Under the stoichiometric framework, predator growth efficiency depends on the prey's variable P:C ratio $Q$ and the predator's constant P:C ratio $\theta$. A portion of the ingested carbon is used for the predator's metabolic costs, such as respiration. Let $\beta_{1}$ be the predator's maximal production efficiency in terms of carbon. Then $\frac{Q}{\beta_{1}}$ is the $\mathrm{P}: \mathrm{C}$ ratio of the post-ingested prey representing the amount of $\mathrm{P}$ and $\mathrm{C}$ available for predator growth. When $\frac{Q}{\beta_{1}}>\theta$, the growth of the predator is limited by carbon and the maximum conversion efficiency is $\beta_{1}$. However when $\frac{Q}{\beta_{1}}<\theta$, the growth of the predator is limited by phosphorus and the maximum conversion efficiency is $\frac{Q}{\theta}$. The predator's conversion efficiency takes the following form:

$$
e(v, x, y)=\min \left\{\beta_{1}, \frac{Q}{\theta}\right\} \max \left\{0,1-\beta_{2} v\right\} .
$$

Note that $\beta_{1}$ corresponds with the parameter $e$ in the LKE model as the predator's conversion efficiency in terms of carbon. A minimum function is used to describe the consumer growth rate, $\min \left\{\beta_{1}, \frac{Q}{\theta}\right\}$. The first input, $\beta_{1}$, is used when consumer growth is limited by carbon. The second input, $\frac{Q}{\theta}$ is used when consumer growth is limited by phosphorus.

Incorporating the stoichiometric logistic growth expression for the prey (4) and conversion efficiency for the predator (6) yields the following toxicant-mediated model that incorporates a 
variable food quantity as well as quality:

$$
\begin{aligned}
& \underbrace{\frac{d x}{d t}}_{\begin{array}{c}
\text { Change in prey } \\
\text { density over time }
\end{array}}=\underbrace{\alpha_{1} \max \left\{0,1-\alpha_{2} u\right\}\left(1-\frac{x}{\min \left\{K, \frac{P-\theta y}{q}\right\}}\right)}_{\begin{array}{c}
\text { gain from } \\
\text { growth }
\end{array}} x-\underbrace{f(x) y}_{\begin{array}{c}
\text { loss from } \\
\text { predation }
\end{array}} \\
& \underbrace{\frac{d y}{d t}}_{\begin{array}{c}
\text { Change in predator } \\
\text { density over time }
\end{array}}=\underbrace{\min \left\{\beta_{1}, \frac{Q}{\theta}\right\} \max \left\{0,1-\beta_{2} v\right\} f(x) y}_{\begin{array}{c}
\text { gain from } \\
\text { growth }
\end{array}}-\underbrace{d_{2}(v) y}_{\begin{array}{c}
\text { loss from } \\
\text { death }
\end{array}} \\
& \underbrace{\frac{d u}{d t}}_{\begin{array}{c}
\text { Change in toxicant } \\
\text { of prey over time }
\end{array}}=\underbrace{a_{1} T}_{\begin{array}{c}
\text { uptake from } \\
\text { water }
\end{array}}-\underbrace{\sigma_{1} u}_{\begin{array}{c}
\text { loss due to } \\
\text { efflux }
\end{array}}-\underbrace{\alpha_{1} \max \left\{0,1-\alpha_{2} u\right\}\left(1-\frac{x}{\min \left\{K, \frac{P-\theta y}{q}\right\}}\right) u}_{\begin{array}{c}
\text { loss due to } \\
\text { growth }
\end{array}} \\
& \underbrace{\frac{d v}{d t}}_{\begin{array}{c}
\text { in toxicant } \\
\text { uptake from } \\
\text { water }
\end{array}}+\underbrace{\xi f(x) u}_{\begin{array}{c}
\text { uptake from } \\
\text { prey }
\end{array}}-\underbrace{\sigma_{2} T}_{\begin{array}{c}
\text { loss due to } \\
\text { efflux }
\end{array}}-\underbrace{\min \left\{\beta_{1}, \frac{Q}{\theta}\right\} \max \left\{0,1-\beta_{2} v\right\} f(x) v}_{\begin{array}{c}
\text { loss due to } \\
\text { growth }
\end{array}} .
\end{aligned}
$$

The biokinetic model (1) corresponds with $\frac{d v}{d t}$ from equation (7d). The original constant ingestion rate $f$ is replaced with function $f(x)$ and depends on prey quantity; the constant predator growth rate $g$ is replaced with the expression $e(v, x, y) f(x)$ and depends on the prey quantity and quality, as well as, the predator's toxicant concentration.

\section{Model parameterization}

We apply the stoichiometric toxicant-mediated predator-prey model (7) to a system of algae (prey) and Daphnia (predator), in order to investigate the effects of co-occuring phosphorus and $\mathrm{Hg}$ availabilities on population dynamics and $\mathrm{Hg}$ bioaccumulation. Details on the parameterization are in Appendix B. All parameter values are listed in Table 1. 


\begin{tabular}{|c|c|c|c|}
\hline & Parameter & Value & Source \\
\hline$\alpha_{1}$ & Algae maximal growth rate & $1.2 /$ day & Andersen (1997) \\
\hline$\alpha_{2}$ & toxicant effect on algal reproduction & $0.0051 \mathrm{mg} \mathrm{C} / \mu \mathrm{g} \mathrm{T}$ & Estimated from data compiled in Vocke (1978)* \\
\hline$K$ & Algae $\mathrm{C}$ carrying capacity & $0-3 \mathrm{mg} \mathrm{C} / \mathrm{L}$ & Andersen (1997) \\
\hline$\beta_{1}$ & Daphnia C growth efficiency & 0.8 (unitless) & Andersen (1997) \\
\hline$\beta_{2}$ & toxicant effect on Daphnia reproduction & $10.13 \mathrm{mg} \mathrm{C} / \mu \mathrm{g} \mathrm{T}$ & Fit to data from Biesinger et al $(1982)^{\dagger}$ \\
\hline$\theta$ & Daphnia constant P:C & $0.03 \mathrm{mg} \mathrm{P} / \mathrm{mg} \mathrm{C}$ & Andersen (1997) \\
\hline$q$ & Algae minimal P:C & $0.0038 \mathrm{mg} \mathrm{P} / \mathrm{mg} \mathrm{C}$ & Andersen (1997) \\
\hline$h_{2}$ & toxicant Coefficient for Daphnia mortality & $0.347 \mathrm{mg} \mathrm{C} / \mu \mathrm{g} \mathrm{T} /$ day & Fit to data from Biesinger et al $(1982)^{\S}$ \\
\hline$I$ & toxicant Exponent for Daphnia mortality & 1.685 (unitless) & Fit to data from Biesinger et al $(1982)^{\S}$ \\
\hline$m_{2}$ & Daphnia natural loss rate & $0.25 /$ day & Andersen (1997) \\
\hline$c$ & Daphnia max ingestion rate & $0.81 /$ day & Andersen (1997) \\
\hline$a$ & Daphnia ingestion half saturation constant & $0.25 \mathrm{mgC} / \mathrm{L}$ & Andersen (1997) \\
\hline$a_{1}$ & Algae uptake coefficient & $0.012 \mathrm{~L} / \mathrm{mg} \mathrm{C} /$ day & Hill and Larsen (2005) \\
\hline$a_{2}$ & Daphnia uptake coefficient & $0.011 \mathrm{~L} / \mathrm{mg} \mathrm{C} /$ day & Tsui and Wang (2004) \\
\hline$\sigma_{1}$ & Algae toxicant efflux rate & $0.048 /$ day & Hill and Larsen (2005) \\
\hline$\sigma_{2}$ & Daphnia toxicant efflux rate & $0.04 /$ day & Tsui and Wang (2004); Karimi et al (2007) \\
\hline$\xi$ & Daphnia toxicant assimilation efficiency & 0.97 (unitless) & Tsui and Wang (2004); Karimi et al (2007) \\
\hline$T$ & Total toxicant & $\mu \mathrm{g} \mathrm{T} / \mathrm{L}$ & \\
\hline$P$ & Total phosphorus & $\mathrm{mg} 0.01-0.08 \mathrm{mg} \mathrm{P} / \mathrm{L}$ & \\
\hline
\end{tabular}

Table 1: Model Parameters. ${ }^{*}$ Parameter estimation discussed in Section Appendix B.2. ${ }^{\dagger}$ Data fitting discussed in Section Appendix B.3.2. ${ }^{\S}$ Data fitting discussed in in Section Appendix B.3.1

\section{Model analysis}

We assume the dynamics of the body burden equations $(7 \mathrm{c}, \mathrm{d})$ operate on a faster time scale than the dynamics of population growth $(7 \mathrm{a}, \mathrm{b})$. The uptake and efflux of the toxicant may balance out and drive the body burden equations to approach a quasi-steady-state. For the model analysis we make this quasi-steady-state assumption to reduce the system down to two equations. Define the small parameter $\epsilon=\alpha_{1} \sigma_{1}$. Note that using the parameters in Table 1 for algae and Daphnia $\epsilon=0.0576$. This small parameter is introduced in the following nondimensionalization. We then analyze the reduced nondimensional system. For mathematical convenience, we assume $I=1$ for the following analysis. The parameterization of this simplifying assumption on the mortality function is discussed in Appendix B.

\subsection{Nondimensionalization and quasi-steady-state approximation}

Here we rescale the Model (7) with the following nondimensional parameters:

$$
\begin{aligned}
\widetilde{u}=\alpha_{2} u, & \widetilde{m_{2}}=\frac{m_{2}}{\alpha_{1}}, \quad \widetilde{\beta}_{1}=\frac{c \beta_{1}}{\alpha_{1}}, \quad \widetilde{\beta}_{2}=\frac{\xi c \sigma_{1} \beta_{2}}{\alpha_{2}}, \\
\gamma=\frac{a_{2} \beta_{2}}{\alpha_{2} a_{1}}, & \widetilde{v}=\beta_{2} v, \quad \epsilon=\alpha_{1} \sigma_{1}, \quad \widetilde{t}=\alpha_{1} t, \\
\widetilde{\sigma_{2}}=\sigma_{2} \sigma_{1}, & \sigma_{1}=\sigma_{1}, \quad \widetilde{T}=\alpha_{2} a_{1} \sigma_{1} T, \quad \widetilde{y}=\frac{c}{\alpha_{1}} y, \\
\widetilde{h_{1}}=\frac{h_{1}}{\alpha_{1} \alpha_{2}}, & \widetilde{h_{2}}=\frac{h_{2}}{\beta_{2} \alpha_{1}}, \quad \widetilde{\theta}=\frac{\alpha_{1} \theta}{c}, \quad \widetilde{Q}=\frac{P-\widetilde{\theta}}{x} .
\end{aligned}
$$


Dropping the tildes for more convenient notation, Model (7) can then be written as the following nondimensional system:

$$
\begin{aligned}
\frac{d x}{d t} & =\max \{0,1-u\}\left(1-\frac{x}{\min \left\{K, \frac{P-\theta y}{q}\right\}}\right) x-\frac{x y}{a+x} \\
\frac{d y}{d t} & =\min \left\{\beta_{1}, \frac{Q}{\theta}\right\} \max \{0,1-v\} \frac{x y}{a+x}-\left(h_{2} v+m_{2}\right) y \\
\epsilon \frac{d u}{d t} & =T-\sigma_{2}^{2} u-\epsilon \max \{0,1-u\}\left(1-\frac{x}{\min \left\{K, \frac{P-\theta y}{q}\right\}}\right) u \\
\epsilon \frac{d v}{d t} & =\gamma T-\sigma_{2} v+\left[\beta_{2} u-\epsilon \min \left\{\beta_{1}, \frac{Q}{\theta}\right\} \max \{0,1-v\} v\right] \frac{x}{a+x}
\end{aligned}
$$

Applying the quasi-steady-state assumption and letting $\epsilon \rightarrow 0$ yields

$$
u=\frac{T}{\sigma_{1}^{2}}, \quad v=\frac{T}{\sigma_{2}}\left(\gamma+\frac{\beta_{2}}{\sigma_{1}^{2}} \frac{x}{a+x}\right) .
$$

Substituting (10) into the $x$ and $y$ equations of System (9) produces the following quasi-steady-state nondimensional system:

$$
\begin{aligned}
& \frac{d x}{d t}=\max \left\{0,1-\frac{T}{\sigma_{1}^{2}}\right\}\left(1-\frac{x}{\min \left\{K, \frac{P-\theta y}{q}\right\}}\right) x-\frac{x y}{a+x} \\
& \frac{d y}{d t}=\min \left\{\beta_{1}, \frac{Q}{\theta}\right\} \max \left\{0,1-\frac{T}{\sigma_{2}}\left(\gamma+\frac{\beta_{2}}{\sigma_{1}^{2}} \frac{x}{a+x}\right)\right\} \frac{x y}{a+x}-\left(\frac{h_{2} T}{\sigma_{2}}\left(\gamma+\frac{\beta_{2}}{\sigma_{1}^{2}} \frac{x}{a+x}\right)+m_{2}\right) y
\end{aligned}
$$

Note that if $T>\sigma_{1}^{2}$ then the toxicant levels are too high for the prey to reproduce and grow and $(x, y) \rightarrow(0,0)$. For the following analysis we assume that $T<\sigma_{1}^{2}$ and let $\mathbf{k}=\min \left\{K, \frac{P}{q}\right\}$.

\subsection{Positive invariance}

Theorem 4.1. Solutions to System (11) with initial conditions in the set

$$
\Omega=\left\{(x, y): 0 \leq x \leq \mathbf{k}=\min \left\{K, \frac{P}{q}\right\}, 0 \leq y, q x+\theta y<P\right\}
$$

will remain there for all forward time.

The proof can be found in Appendix D

\subsection{Asymptotic dynamics}

To investigate the equilibria we first rewrite System (11) in the following form:

$$
\begin{aligned}
& \frac{d x}{d t}=x F(x, y) \\
& \frac{d y}{d t}=y G(x, y)
\end{aligned}
$$


where

$$
\begin{aligned}
& F(x, y)=\max \left\{0,1-\frac{T}{\sigma_{1}^{2}}\right\}\left(1-\frac{x}{\min \left\{K, \frac{P-\theta y}{q}\right\}}\right)-\frac{y}{a+x} \\
& G(x, y)=\min \left\{\beta_{1}, \frac{Q}{\theta}\right\} \max \left\{0,1-\frac{T}{\sigma_{2}}\left(\gamma+\frac{\beta_{2}}{\sigma_{1}^{2}} \frac{x}{a+x}\right)\right\} \frac{x}{a+x}-\left(\frac{h_{2} T}{\sigma_{2}}\left(\gamma+\frac{\beta_{2}}{\sigma_{1}^{2}} \frac{x}{a+x}\right)+m_{2}\right)
\end{aligned}
$$

The Jacobian takes the following form:

$$
J=\left|\begin{array}{cc}
F(x, y)+x F_{x}(x, y) & x F_{y}(x, y) \\
y G_{x}(x, y) & G(x, y)+y G_{y}(x, y)
\end{array}\right| .
$$

There are two equilibria on the boundary, $E_{0}=(0,0)$ and $E_{1}=(\mathbf{k}, 0)$. The following theorem shows local stability of these boundary equilibria.

Theorem 4.2. $E_{0}=(0,0)$ is saddle point. The stability of $E_{1}=(\mathbf{k}, 0)$ depends on the sign of $G(\mathbf{k}, 0) . E_{1}$ is locally asymptotically stable if $G(\mathbf{k}, 0)<0$ and $E_{1}$ is saddle point if $G(\mathbf{k}, 0)>0$.

The proof can be found in Appendix E

Figure 2 illustrates phase portraits with the prey x-nullclines and the predator $y$-nullclines for varying levels of light. Equilibria are located at the intersection of these nullclines. In addition to the two boundary equilibria $E_{0}$ and $E_{1}$, numerical observations show the existence of three interior equilibria $E_{2}, E_{3}$, and $E_{4}$. As light levels vary, the shape of the x-nullcline changes which affects the number and the nature of the interior equilibria. For low light (Figure 2a) there is one interior equilibria, $E_{2}$. Numerical observations show this is locally stable. For high light (Figure $2 \mathrm{~b}$ ) this interior equilibria $E_{3}$ becomes unstable and a stable limit cycles emerges. Under very high light (Figure 2c) there are three interior equilibria $E_{2}, E_{3}$, and $E_{4}$. Here the limit cycles have collapsed and $E_{4}$ is locally stable.

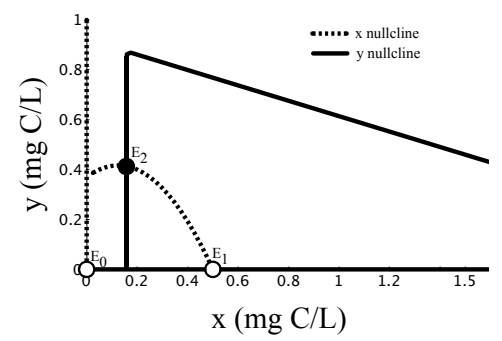

(a)

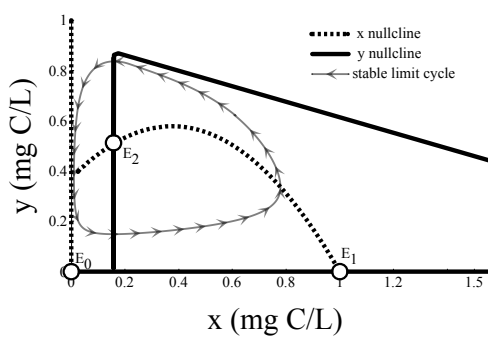

(b)

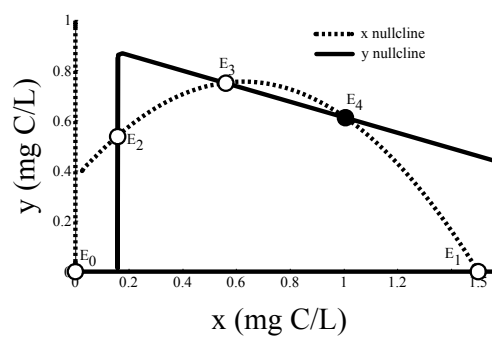

(c)

Figure 2: Predator-prey phase portraits for varying light levels a.) low light $K=0.5 \mathrm{mg} \mathrm{C} / \mathrm{L} \mathrm{b}$.) high light $K=1 \mathrm{mg} \mathrm{C} / \mathrm{L} \mathrm{c.)} \mathrm{very} \mathrm{high} \mathrm{light} K=1.5 \mathrm{mg} \mathrm{C} / \mathrm{L}$. The x-nullclines are dashed curves and the y-nullcline are solid curves. Open circles depict unstable equlibria and closed circles depict locally stable equilibria. Points $E_{0}$ and $E_{1}$ are boundary equilibria. Points $E_{2}, E_{3}$, and $E_{4}$ are interior equilibria. The grey arrowed-curve in figure b. shows a stable limit cycle. Parameter values listed in Table 1 with $P=0.03$ $\mathrm{mg} \mathrm{P} / \mathrm{L}$ and $T=0.025 \mu \mathrm{g} \mathrm{MeHg} / \mathrm{L}$. Population dynamics are similar to those obtained in Loladze et al (2000).

\section{Numerical analysis}

Loladze et al (2000) investigate the effects of light enrichment on the basic stoichiometric predator-prey model (System (A.1)). Peace et al (2013) investigate the effects of nutrient enrichment 
on an expanded stoichiometric predator-prey model. It is observed that increasing light levels $K$ causes the prey food quality $Q$ to decrease, whereas increasing the nutrient levels $P$ causes the prey food quality to increase. Here we numerically explore how stoichiometric constraints affect the populations densities and the trophic transfer of the toxicant. We vary the light level $K$, in order to manipulate the prey food quality. Additionally, we investigate the effects of increasing toxicant concentrations $T$ on the population dynamics. Simulations from numerical experiments are presented in Section 5.1 and bifurcation analyses are presented in Section 5.2.

\subsection{Numerical simulations}

These simulations use the parameters listed in Table 1 with $P=0.03 \mathrm{mg} \mathrm{P} / \mathrm{L}$ for varying light intensities $K$ (Figure 3 ) and varying toxicant concentrations $T$ (Figure 4).

Figure 3 shows the population densities, food quality, body burden, and phase portraits predicted by model (7) for three different light levels $K=0.5,1,1.5 \mathrm{mg} \mathrm{C} / \mathrm{L}$ and a fixed toxicant level. The food quality $Q$ predictions (3def) follow from equation (5). Under low light, the system exhibits a stable steady state where the population densities $x, y$ are low (3a), food quality $Q$ is high (3d), and predator body burden $u$ is low $(3 \mathrm{~g})$. Here $y$ is low due to low food quantity. Increasing the light level to high light causes a Hopf bifurcation to occur as the steady state looses stability and limit cycles emerge (3beh). The limit cycles collapse as the light level continues to increase. Under very high light, the system exhibits another stable steady state where the population density $x$ is high but $y$ is low (3c), food quality $Q$ is low (3f), and predator body burden $v$ is high (3g). Here $y$ is low due to low food quality rather than quantity. The low food quality (3f) has significant influences on the predator population; reducing the density (3c) and increasing the body burden (3i). The Somatic Growth Dilution (SGD) effect is seen when comparing the food quality and body burden under low light (3dg) versus very high light (3fi).

Asymptotic dynamics can been seen in the phase portraits (Figure $3 \mathrm{jkl}$ ). Under low light levels, the interior equilibria $E_{2}$ is stable (3j). The existence of a stable limit cycle is observed under high light (3k). Under very high light levels, the interior equilibria $E_{4}$ is stable (3l). 

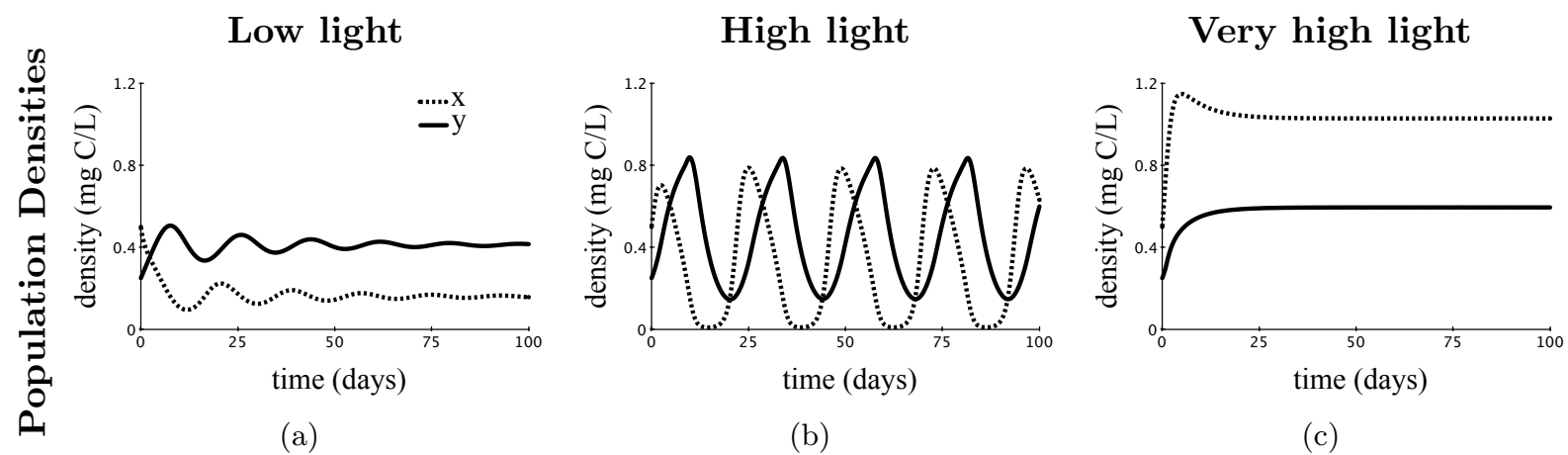

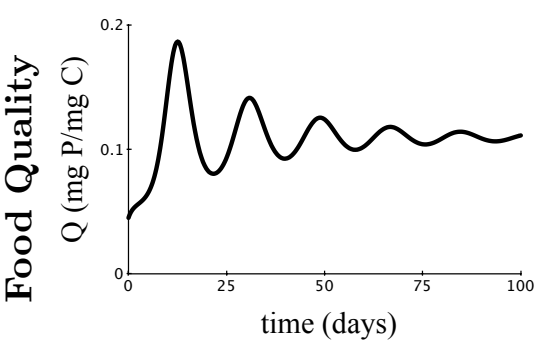

(d)

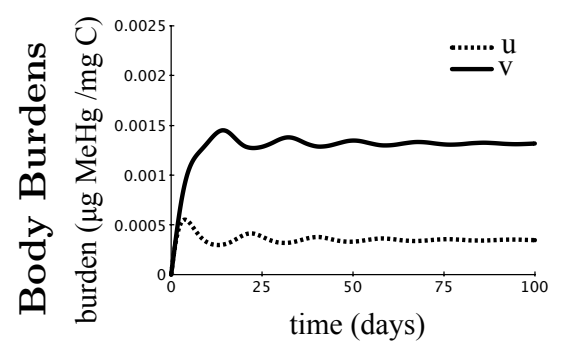

(g)

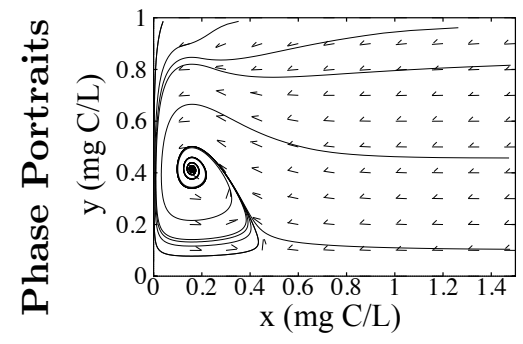

(j)

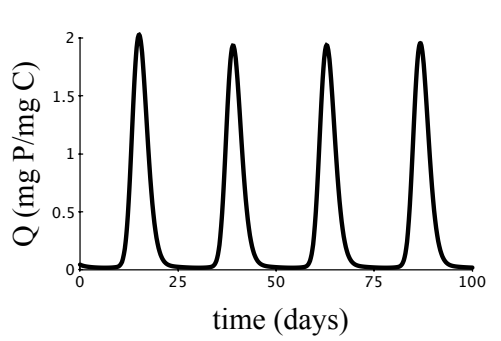

(e)

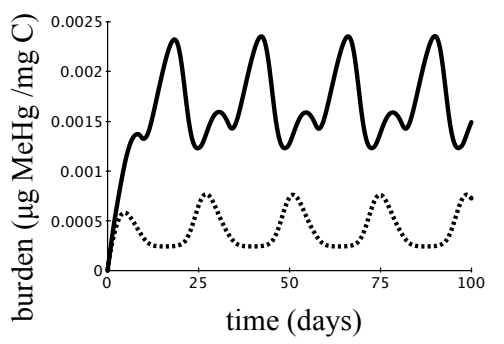

(h)

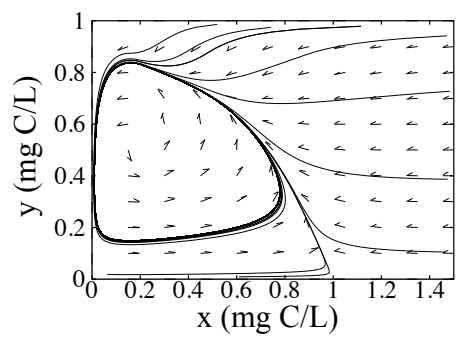

(k)

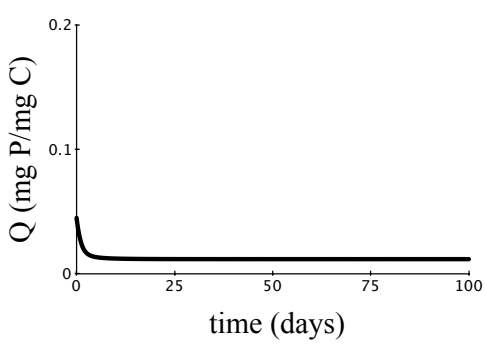

(f)

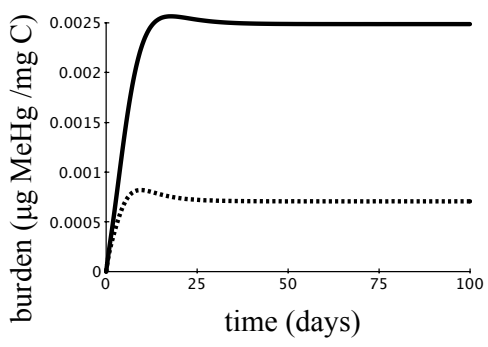

(i)

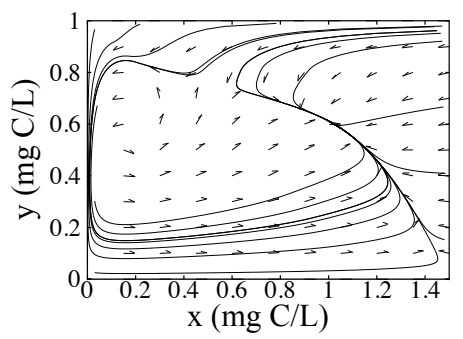

(1)

Figure 3: Numerical simulations for abc.) population densities $x$ (dashed), $y$ (solid) mg C/L, def.) algal quota $Q \mathrm{mg} \mathrm{P} / \mathrm{mgC}$, ghi.) body burdens $u$ (dashed), $v$ (solid) $\mu \mathrm{g} \mathrm{MeHg} / \mathrm{mg} \mathrm{C}$, and jkl.) phase portraits for three different light intensities: low light $K=0.5 \mathrm{mg} \mathrm{C} / \mathrm{L}$ (column one), high light $K=1 \mathrm{mg} \mathrm{C} / \mathrm{L}$ (column two), and very high light $K=1.5 \mathrm{mg} \mathrm{C} / \mathrm{L}$ (column three). Parameter values listed in Table 1 with $P=0.03 \mathrm{mg} \mathrm{P} / \mathrm{L}$ and $T=0.025 \mu \mathrm{g} \mathrm{MeHg} / \mathrm{L}$. Data obtained using MATLAB and XPP. Population dynamics are similar to those obtained in Loladze et al (2000).

Figure 4 shows the population densities, food quality, body burden, and phase portraits predicted predicted by model (7) for three different toxicant levels $T=0.5,0.75,1 \mu \mathrm{g} \mathrm{MeHg} / \mathrm{L}$ and a fixed light level. The food quality $Q$ predictions (4def) follow from equation (5). Under low toxicant 
contamination, the system exhibits limit cycles for this fixed light level $K=0.6 \mathrm{mg} \mathrm{C} / \mathrm{L}$ (4adg). Increasing the toxicant contamination collapses the limit cycles as the system passes the Hopf bifurcation and exhibits a stable steady state (4beh). Increasing the toxicant contamination further leads the predator population to extinction (4c). Here the prey actually benefits from high contamination levels. According to the parameter values obtained, the algae are much less sensitive to $\mathrm{MeHg}$ contamination than Daphnia and the extinction of the predator relieves predation pressure off the prey (4c). The increased population density of the prey $x$, under high contamination, reduces the prey food quality $Q(4 \mathrm{f})$. The body burdens $u, v$ increase as the toxicant levels increase. Under high contamination the predator body burden $v$ increases very rapidly as the predator goes towards extinction $y \rightarrow 0$ (4i). Note the difference in the scale on the vertical axes of Figures $4 \mathrm{~g}$, h, and i.

Asymptotic dynamics can been seen in the phase portraits (Figure $4 \mathrm{jkl}$ ). Under low toxicant contamination, there exists of a stable limit cycle $(4 \mathrm{j})$. The interior equilibria $E_{4}$ is stable under high contamination (3k). Under very high contamination, there are no stable interior equilibria or limit cycles and boundary equilibria $E_{1}$ is stable. Here the very high toxicant levels drives the predator to extinction. 


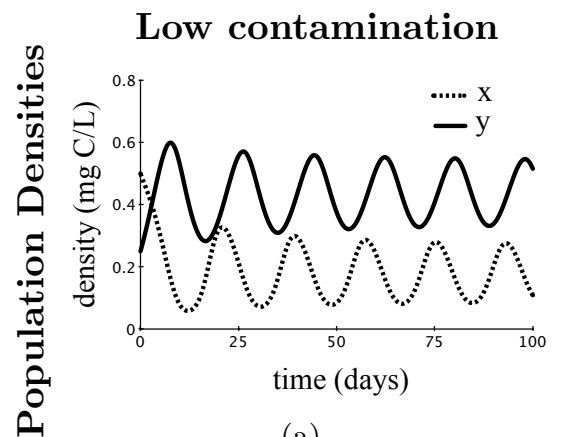

(a)

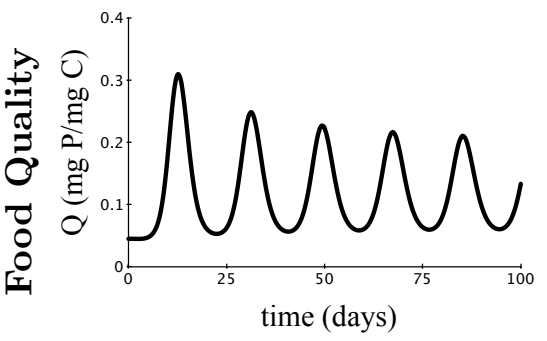

(d)

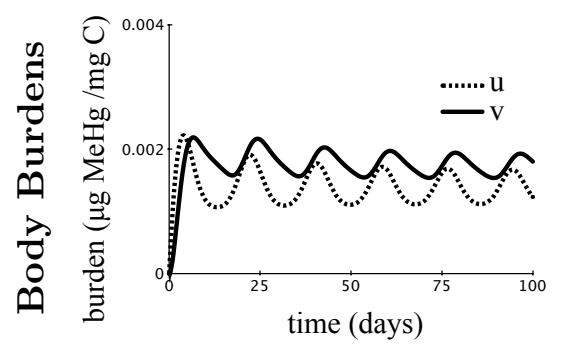

(g)

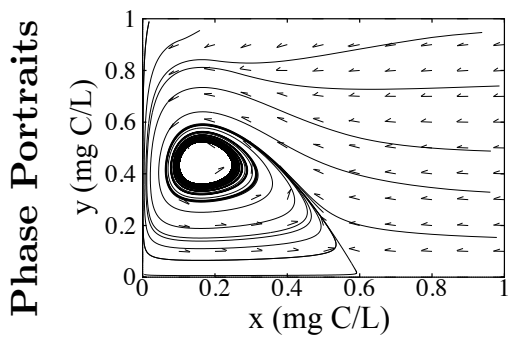

(j)

\section{High contamination}

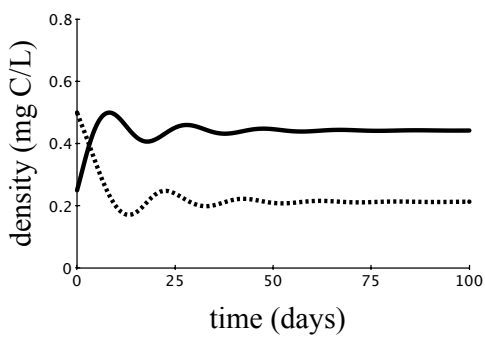

(b)

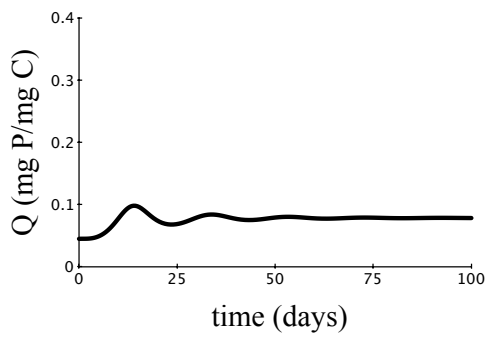

(e)

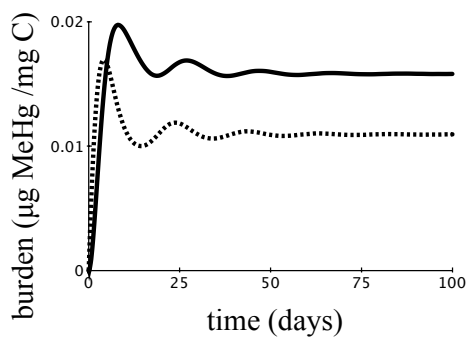

(h)

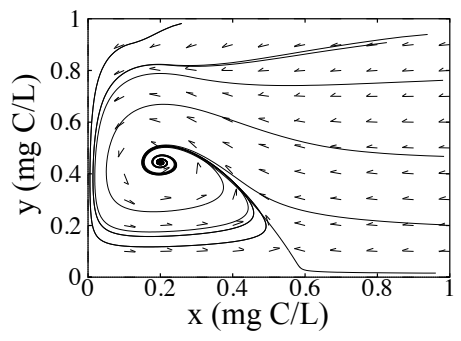

(k)
Very high contamination

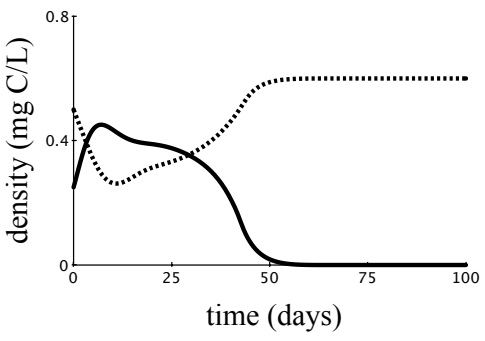

(c)

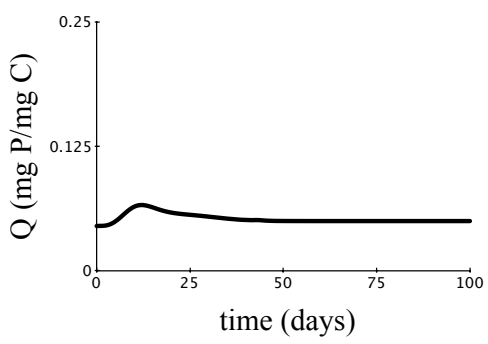

(f)

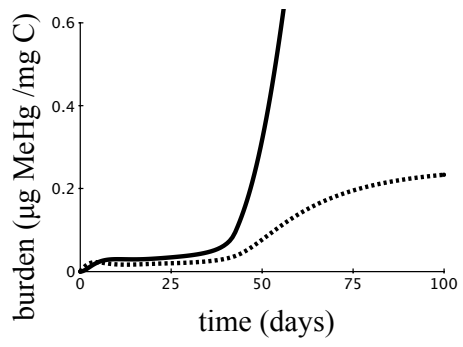

(i)

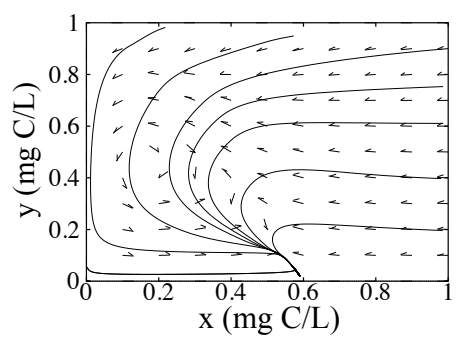

(1)

Figure 4: Numerical simulations for abc.) population densities $x$ (dashed), $y$ (solid) mg C/L, def.) algal

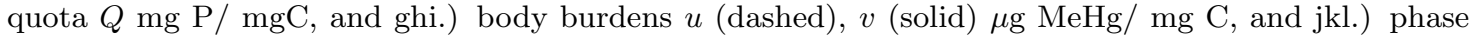
portraits for three different $\mathrm{MeHg}$ toxicant levels: low contamination $T=0.1 \mu \mathrm{g} \mathrm{MeHg} / \mathrm{L}$ (column one), medium contamination $T=0.5 \mu \mathrm{g} \mathrm{MeHg} / \mathrm{L}$ (column two), and high contamination $T=1 \mu \mathrm{g} \mathrm{MeHg} / \mathrm{L}$ (column three). Parameter values listed in Table 1 with $P=0.03 \mathrm{mg} \mathrm{P} / \mathrm{L}$ and $K=0.6 \mathrm{mg} \mathrm{C} / \mathrm{L}$. Data obtained using MATLAB and XPP.

\subsection{Bifurcation analysis}

Bifurcation diagrams for the predator population density $y$, the total amount of toxicant in the predator population $V$, and the predator body burden $v$ are shown in Figures 5 and 6 . 
Figure 5 uses the light level $K$ as the bifurcation parameter. These bifurcations are similar to those obtained in the LKE model (Loladze et al, 2000) and globally investigated by Van Voorn et al (2010), Li et al (2011), and Xie et al (2016). When light levels are very low there is not enough energy in the system to support the predator population. As $K$ increases, a stable steady state emerges. The predator population starts off at low density (5a) with low body burden (5c). As $K$ continues to increase, the predator density increases until the stable steady state looses it's stability and limit cycles emerge at a Hopf bifurcation. This is the well known "paradox of enrichment" (Rosenzweig et al, 1971; Diehl, 2007). Eventually, as $K$ increases further, another bifurcation occur where the limit cycles collapse and a new interior stable state appears. For the LKE model, Van Voorn et al (2010) found this bifurcation to be a homoclinic bifurcation coinciding with a tangent bifurcation where a saddle-node homoclinic connection is formed. After this bifurcation the predator density will begin to decrease as $K$ increases to very high values. This decline in predator density caused by high light levels is a phenomenon called the "paradox of energy enrichment" (Loladze et al, 2000). At high light levels, the low density predator population has high body burden (5c). The SGD effect is observed when comparing the body burden values on the left (low $K$ ) with the values on the right (high $K$ ) in Figure 5c. Food quality $Q$ is high for low light levels and is low for high light levels.

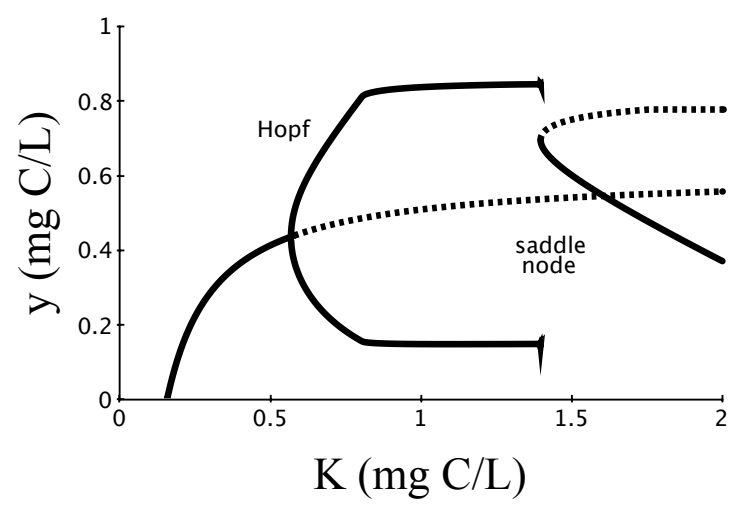

(a)

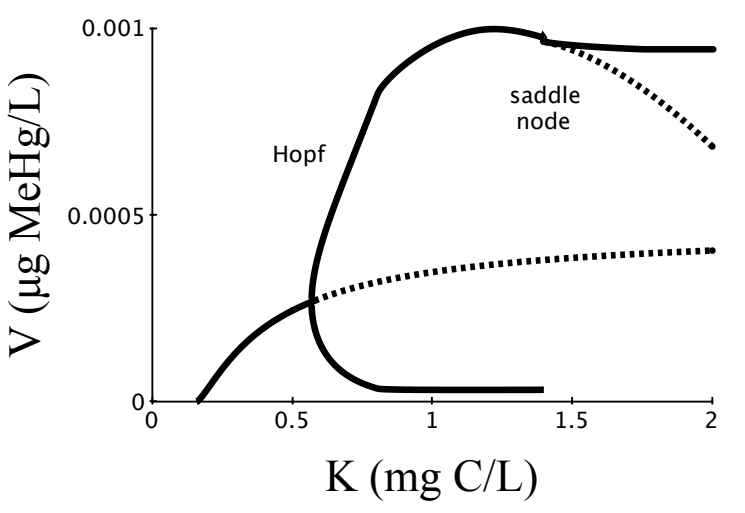

(b)

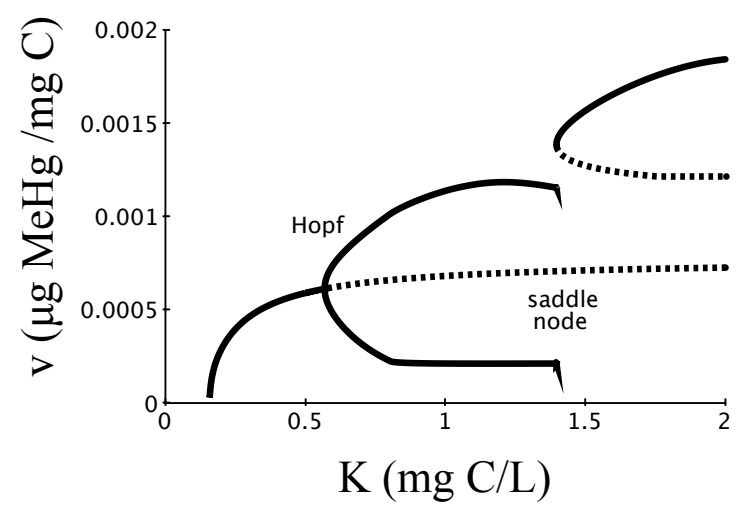

(c)

Figure 5: Bifurcation diagrams for a.) $y$ predator biomass b.) $V$ total toxicant in predator population c.) $v$ predator body burden using bifurcation parameter $K \mathrm{mg} \mathrm{C} / \mathrm{L}$. Solid curves depict stable equilibria and limit cycles and dashed curves depict unstable equilibria. The solid curves in between the Hopf and saddle node bifurcations depict the maximum and minimum values of the stable limit cycle. Parameter values listed in Table 1 with $P=0.03 \mathrm{mg} \mathrm{P} / \mathrm{L}$ and $T=0.025 \mu \mathrm{g} \mathrm{MeHg} / \mathrm{L}$. Data generated using XPP-AUTO. Population dynamics are similar to those obtained in Loladze et al (2000) and globally investigated in Van Voorn et al (2010), Li et al (2011), and Xie et al (2016). 
Figure 6 uses the toxicant contamination level $T$ as the bifurcation parameter and a fixed light level $K=0.6 \mathrm{mg} \mathrm{C} / \mathrm{L}$. Under this parameterization, the system exhibit limit cycles for low toxicant levels. As $T$ increases, the limit cycles collapse at the Hopf bifurcation and a stable steady state emerges. The predator population experience a slight decrease as $T$, and therefore their body burden $v$ increases. Eventually, for very high $T$ levels not shown in the diagrams, the predator population will decline to extinction.

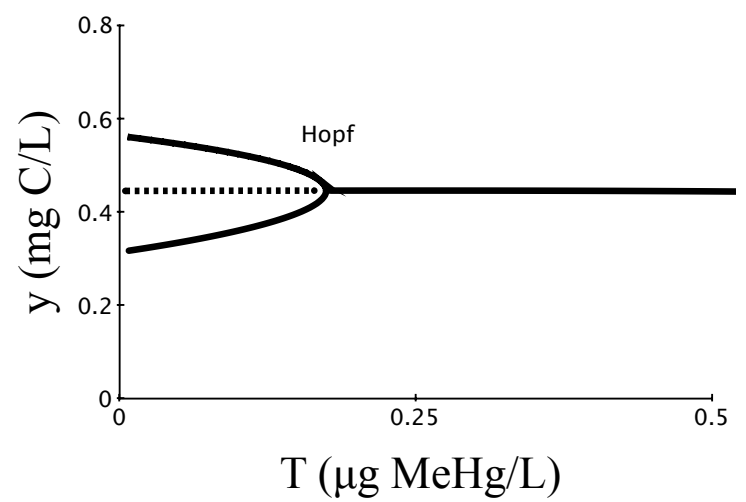

(a)

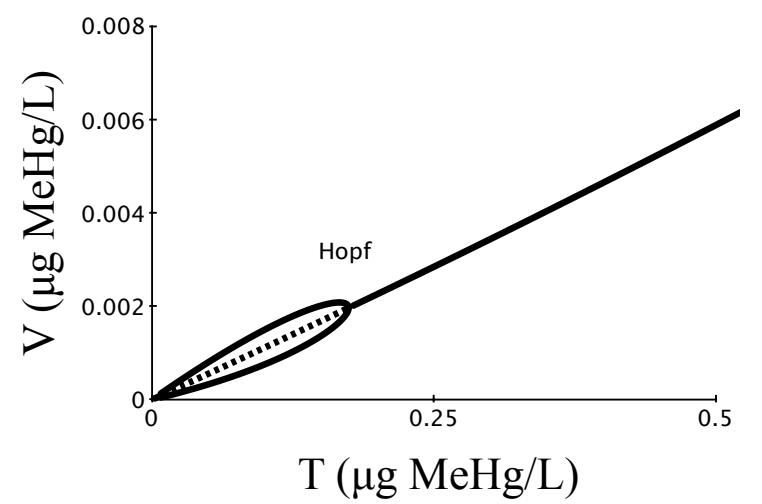

(b)

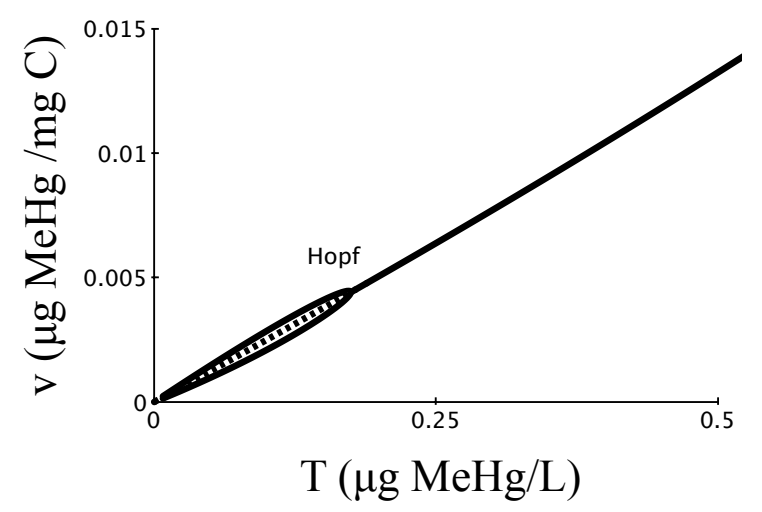

(c)

\begin{abstract}
Figure 6: Bifurcation diagrams for a.) $y$ predator biomass b.) $V$ total toxicant in predator population c.) $v$ predator body burden using bifurcation parameter $T \mu \mathrm{g} \mathrm{MeHg} / \mathrm{L}$. Solid curves depict stable equilibria and limit cycles and dashed curves depict unstable equilibria. The solid curves prior to the Hopf bifurcations depict the maximum and minimum values of the stable limit cycle. Parameter values listed in Table 1 with $P=0.03 \mathrm{mg} \mathrm{P} / \mathrm{L}$ and $K=0.6 \mathrm{mg} \mathrm{C} / \mathrm{L}$. Data generated using XPP-AUTO.
\end{abstract}

\title{
6. Discussion
}

The development of ecotoxicological models over the last couple decades have significantly contributed to interpreting how contaminants impact organisms and cycle through aquatic food webs (Hallam and De Luna, 1984; Ankley et al, 1995; Kooijman and Bedaux, 1996; Wang et al, 1996; Mackay et al, 1992; Pieters et al, 2006; Ashauer et al, 2007; Wang and Rainbow, 2008; Ashauer and Brown, 2008; Bontje et al, 2009; Huang et al, 2014). These modeling efforts take a variety of approaches to predict the effects of diverse chemical contaminants on organismal growth and survival. Many of these models assume the food quantity and quality are constant. (Huang et al (2014) and Pieters et al (2006) incorporate variable food quantities in their models but do not consider variable food quality.) However, there is increasing evidence that organisms experience 
interactive effects of contaminant stressors and food conditions, such as resource stoichiometry and nutrient availability (Danger and Maunoury-Danger, 2013).

We developed a model that expands conventional toxicological approaches that only consider constant food quantity and quality using the framework of Ecological Stoichiometry (Sterner and Elser, 2002). Model 7 incorporates the effects of concurrent nutrient and toxicant stressors on population dynamics and the trophic transfer of toxicants. While the model can be generalized to a variety of aquatic species and chemicals, we parameterized model 7 to an algae-Daphnia system that investigates levels of phosphorus, carbon (light), and $\mathrm{MeHg}$.

In order to analytically analyze the model, we employed a quasi-steady-state assumption to reduce the model down to two dimensions. We assumed population metabolism occurs on a faster time scale than population growth dynamics. Analytical analysis of the reduced model (System 11) shows the model is positive and bounded. We analytically investigated the existence and local stability of boundary equilibria. The existence and stability of interior equilibria and limit cycles were observed numerically.

Recent data show that the interactive effects of nutrient availability and aqueous $\mathrm{Hg}$ concentration may play a significant role in the bioaccumulation of $\mathrm{MeHg}$. The model is used to explored the effects of varying light levels and toxicant concentrations on population dynamics and the flow of $\mathrm{MeHg}$ across the two trophic levels. The model captures the Somatic Growth Dilution (SGD) phenomenon, which has been observed empirically in Daphnia contaminated with $\mathrm{MeHg}$, as they experience a greater than proportional gain in biomass relative to $\mathrm{MeHg}$ under high phosphorus concentrations (Karimi et al, 2007). SGD can be seen in the numerical simulations and bifurcation analysis (Section 5).

It is important to note that the nonstoichiometric toxicant-mediated predator prey model developed by Huang et al (2014), model (3) and the stoichiometric model developed here, model (7) ignore the influences of the populations on the toxicant in the environment. Environmental toxicant concentration is treated as a parameter, $T$. These models assume the toxicant concentrations in the environment are determined by external conditions and are not regulated by the population dynamics. This assumption is reasonable because the toxicant contained in the studied populations is a tiny portion of the environmental toxicant.

The model developed here integrates an a ecotoxicological model into the theory of Ecological Stoichiometry. Equations (4) and (6) are an initial attempt at coupling toxicant and nutrient stressors in the growth functions of the prey and predator. Here we assume the organisms pay an energy or carbon cost when exposed to contaminants, that reduce the growth rates based on a linear dose response of growth to concentrations of the toxicant. The model allows us to mathematically explore toxicant-induced carbon costs. It is important to note that this initial model iteration assumes the toxicant-induced costs is paid in carbon.

Future model iterations should consider the impact of contaminants on organism elemental compositions. In addition to influencing life history traits specific contaminants can impact organism elemental composition (Danger and Maunoury-Danger, 2013). This phenomenon has recently been observed: Wang et al (2008b) observed plants have lower nitrogen leaf concentrations when exposed to cadmium, and Xing et al (2010) observed aquatic plants have lower nitrogen and phosphorus concentrations when exposed to iron or copper. Some chemical contaminants have the ability to alter an organism's physiology, such as their stoichiometric P:C ratio. Such impacts on the elemental composition will alter the elemental balances between the organisms and their consumed resources, resulting in stoichiometric constraints that will in turn influence population dynamics. More work is needed that focuses on how toxicants impact elements compositions. Future directions can mathematically and empirically explore toxicant-induced nutrient costs, in addition to the toxicant-induced carbon costs incorporated in the model presented here. 


\section{Acknowledgements}

Part of this work was conducted while Angela Peace was Postdoctoral Fellow at the National Institute for Mathematical and Biological Synthesis, an Institute sponsored by the National Science Foundation through NSF Award \#DBI-1300426, with additional support from The University of Tennessee, Knoxville. Hao Wang's research is partially supported by an NSERC grant.

\section{Appendix A. LKE model with slight modification}

Loladze et al (2000) formulated a stoichiometric prey-predator Lotka-Volterra type model (LKE model) of the first two trophic levels of an aquatic food chain incorporating the fact that both preys and predators are chemically heterogeneous organisms composed of two essential elements, carbon (C) and phosphorus $(\mathrm{P})$. The model allows the phosphorus to carbon ratio $(\mathrm{P}: \mathrm{C})$ of the prey to vary above a minimum value, which brings food quality into the model. Below is the LKE model presented by Loladze et al (2000).

$$
\begin{aligned}
& \frac{d x}{d t}=\alpha_{1} x\left(1-\frac{x}{\min \left\{K, \frac{P-\theta y}{q}\right\}}\right)-f(x) y \\
& \frac{d y}{d t}=e \min \left\{1, \frac{Q}{\theta}\right\} f(x) y-d_{2} y
\end{aligned}
$$

where

$$
Q=\frac{P-\theta y}{x}
$$

and $\alpha_{1}$ is the prey maximum growth rate, $K$ is the prey carrying capacity in terms of carbon or light availability, $P$ is the total about of phosphorus in the system, $\theta$ is the constant predator $\mathrm{P}: \mathrm{C}$ ratio, $\mathrm{Q}$ is the variable prey $\mathrm{P}: \mathrm{C}$ ratio, and $q$ is the minimum $\mathrm{P}: \mathrm{C}$ ratio of the prey.

Here, a minimum function is used to describe the prey carrying capacity, $\min \{K,(P-\theta y) / q\}$. The first input, $K$, is the carrying capacity determined by light availability. The second input, $(P-\theta y) / q$ is the carrying capacity determined by phosphorus availability. Another minimum function is used to describe the consumer growth rate, $\min \left\{1, \frac{Q}{\theta}\right\}$. The first input, 1 , is used when consumer growth is limited by carbon. The second input, $\frac{Q}{\theta}$ is used when consumer growth is limited by phosphorus.

Here we make a small modification to the LKE model (A.1) to put $e$ inside the minimum function in the expression for predator's growth. It is well known that not all carbon biomass of the prey ends up as carbon biomass of the predator. Some carbon is used for metabolic processes, such as respiration. This is represented by the predator's conversion efficiency $e<1$. Its important to note that this constant is defined in terms of carbon. Therefore $Q / e$ is the $\mathrm{P}: \mathrm{C}$ of the post ingested prey available for predator's growth. Consider $g(x, y)$ the predator's growth rate. When $\frac{Q}{e}>\theta$, the growth of the predator is limited by carbon and satisfies $g(x, y)=f(x) e$. However when $\frac{Q}{e}<\theta$, the growth of the predator is limited by phosphorus and satisfies $g(x, y) \theta=f(x) Q$. Together, these two cases can be written as:

$$
g(x, y)=\left\{\begin{array}{ll}
\frac{Q}{\theta} f(x) & \text { for } \frac{Q}{e}<\theta \\
e f(x) & \text { for } \frac{Q}{e}>\theta
\end{array}\right\}=\min \left\{e, \frac{Q}{\theta}\right\} f(x)
$$




\section{Appendix B. Parameterization}

\section{Appendix B.1. Nontoxicant-related parameters}

Many of the nontoxicant-related parameters of algae and Daphnia population dynamics are biologically realistic values obtained from Andersen (1997); Urabe and Sterner (1996) and used in Loladze et al (2000).

The predator's ingestion rate, $f(x)$ is a monotonic increasing and differentiable function, $f^{\prime}(x) \geq$ $0, f(0)=0 . f(x)$ is saturating with $\lim _{x \rightarrow \infty} f(x)=c$. For the following analysis, we assume the ingestion rate is a Holling type II function of the following form,

$$
f(x)=\frac{c x}{a+x}
$$

where $c$ is the maximal Daphnia ingestion rate and $a$ is the half saturation constant.

\section{Appendix B.2. Prey toxicant-related parameters}

Hill and Larsen (2005) examined the uptake and elimination of $\mathrm{Hg}$ by microalgal biofilms. Their experiment involved observing microalgal biofilm $\mathrm{Hg}$ accumulation over a two day period where they measured the algae $\mathrm{Hg}$ uptake coefficient to be $a_{1}=0.0123 \mathrm{~L} / \mathrm{mgC} /$ day. They also observed the $\mathrm{Hg}$ loss rate by microalgal biofilms over a four day period and calculated the algal $\mathrm{Hg}$ efflux rate to be $\sigma_{1}=0.048 /$ day.

In order to estimate the effect of the toxicant on algae growth, consider the threshold body burden at which algae is no longer capable of growth. Following Huang et al (2015), this threshold body burden can be described with the following equation,

$$
\frac{1}{\alpha_{2}}=\frac{a_{1}}{\sigma_{1}} T_{0}
$$

where $T_{0}$ is the concentration of toxicant that inhibits algal growth $100 \%$. Vocke (1978) compiled data of growth responses reported for freshwater algae exposed to Hg. Relevant data from Vocke (1978) on threshold $\mathrm{Hg}$ concentrations that resulted in 100\% growth inhibition for various algal species is shown in Appendix $\mathrm{C}$. The average $\mathrm{Hg}$ concentration threshold for complete inhibited growth across these species is $T_{0}=0.7843 \mathrm{mg} / \mathrm{L}$. Using this $T_{0}$ along with the above parameters for $a_{1}$ and $\sigma_{1}$ and Equation (B.1), we estimate $\alpha_{2}=0.0051 \mathrm{mg} \mathrm{C} / \mu \mathrm{g}$ toxicant.

\section{Appendix B.3. Predator toxicant-related parameters}

Tsui and Wang (2004) examined the assimilation, dissolved uptake, and efflux of $\mathrm{Hg}$ and $\mathrm{MeHg}$ in Daphnia magna. They report the Daphnia uptake coefficient for dissolved $\mathrm{MeHg}$ in the water is $a_{2}=0.011 \mathrm{~L} / \mathrm{mg} \mathrm{C} /$ day. The Daphnia efflux rate for $\mathrm{MeHg}$ is $\sigma_{2}=0.04 /$ day and the assimilation efficiency is 0.97. Karimi et al (2007) reported similar values for $a_{2}$ and $\sigma_{2}$.

\section{Appendix B.3.1. Toxicant-dependent predator mortality rate}

Here we use the power law to represent the relationship between toxicant concentrations and predator mortality rate, as recommended by the committee on toxicology of the National Research Council in 1992 and tested in Miller et al (2000). Predator mortality rate as a function of $v$, the concentration of the toxicant in the predator (body burden), takes the following form

$$
d_{2}(v)=h_{2} v^{I}+m_{2}
$$

where $h_{2}$ and $I$ are positive constants for the coefficient and exponent of the power function and $m_{2}$ is the natural loss rate, including both natural mortality and respiration. The natural loss rate for 
Daphnia is known to be $m_{2}=0.25$ /day (Andersen, 1997). To parameterize this mortality function we used data presented by Tsui and Wang (2006) on the percent survival of juvenile Daphnia magna after 24 hours of exposure to treatments of 1.5-7 $\mu \mathrm{g} \mathrm{Hg} / \mathrm{L}$. Huang et al (2013) described the relationship between the probability of mortality after $t$ days $\left(p_{0}(t)\right)$ and body burden $(v)$ as

$$
p_{0}(t)=1-\exp \left(-h_{2} v^{I} t\right) \text {. }
$$

Following Huang et al (2013), we took the above mortality function (B.3) and used MATLAB's LSQCURVEFIT to fit the data presented by Tsui and Wang (2006). We obtained parameter values $h_{2}=0.347 \mathrm{mg} \mathrm{C} / \mu \mathrm{g}$ toxicant/day and $I=1.685$. Figure B.7 shows the experimental data from Tsui and Wang (2006) and the mortality function (B.3) with the obtained parameter values. It is convenient to assume $I=1$ for the analytical analysis presented in Section 4. Using this simplifying assumption, the mortality function (B.3) becomes $p_{0}(t)=1-\exp \left(-h_{2} v t\right)$ where $h_{2}=0.0949 \mathrm{mg}$ $\mathrm{C} / \mu \mathrm{g}$ toxicant/day when fit to the data. Figure B.7 shows this simplified mortality function with the assumption that $I=1$ is comparable to the mortality function (B.3). In this manuscript, numerical simulations use the empirical mortality function parameter fits $\left(h_{2}=0.347 \mathrm{mg} \mathrm{C} / \mu \mathrm{g}\right.$ toxicant/day, $I=1.685)$ and the analytical analysis assumes the simplified parameter values $\left(h_{2}=0.0949 \mathrm{mg}\right.$ $\mathrm{C} / \mu \mathrm{g}$ toxicant/day, $I=1)$.

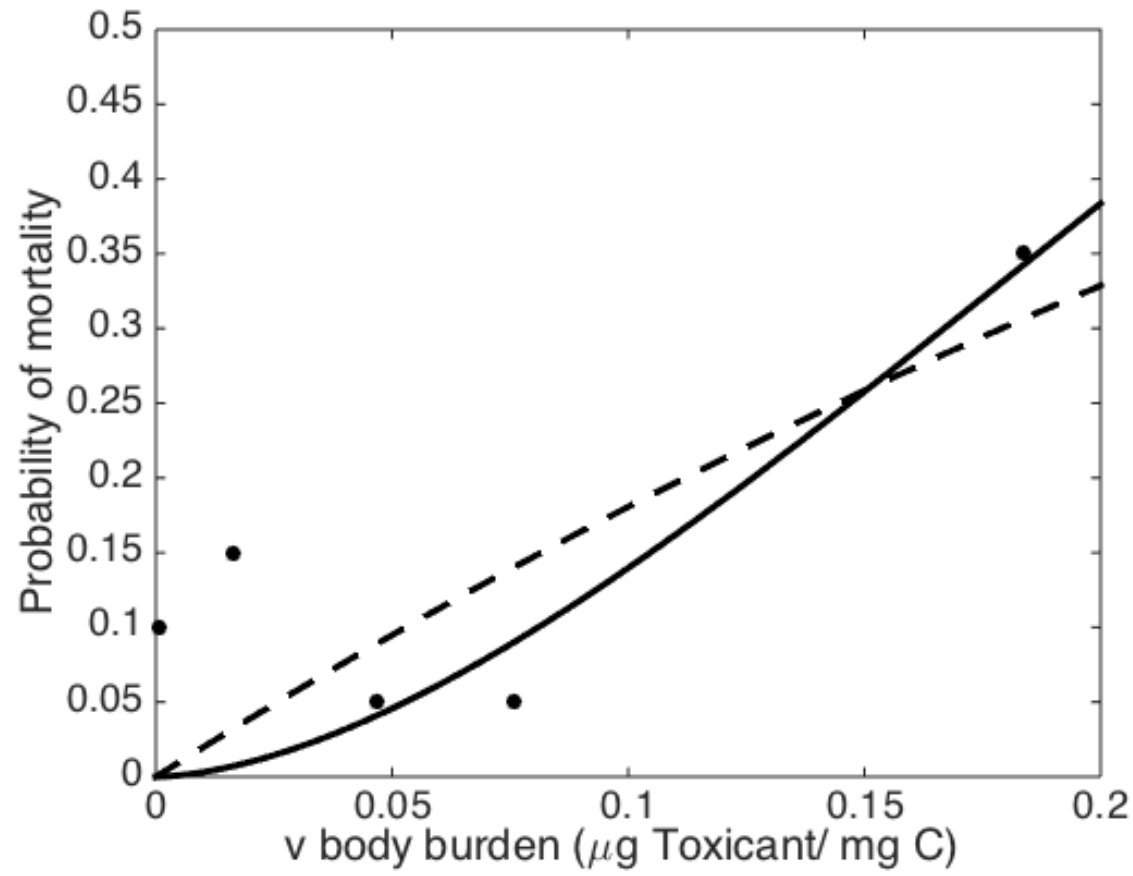

Figure B.7: Experimental data from Biesinger et al (1982) of Daphnia magna exposed to MeHg for 21 days and the mortality function (B.3) with the obtained parameter values using MATLAB's LSQCURVEFIT to fit the data. The solid curve gives the empirical mortality function with parameters $h_{2}=0.347 \mathrm{mg} \mathrm{C} / \mu \mathrm{g}$ toxicant/day and $I=1.685$. The dashed curve gives the simplified mortality function with parameters $h_{2}=0.0949 \mathrm{mg} \mathrm{C} / \mu \mathrm{g}$ toxicant/day and $I=1$.

\section{Appendix B.3.2. Toxicant-dependent predator reproduction efficiency}

We use the following linear dose response to represent the effect of the toxicant on the reproduction of the predator

$$
\max \left\{0,1-\beta_{2} v\right\}
$$


which represents a linear dose response for the reproduction efficiency (Huang et al $(2013,2014)$ ). Here we are making a simplifying assumption and only consider the effect of the toxicant on the reproduction and not on individual growth. If the predator body burden, $v$, reaches the threshold $\frac{1}{\beta_{2}}$ the reproduction efficiency is zero and reproduction ceases. To parameterize this reproduction function we used MATLAB's LSQCURVEFIT to fit the data presented by Biesinger et al (1982) on the average number of neonates produced by Daphnia magna throughout 21 days of exposure to MeHg. We assumed the number of neonates produced by Daphnia magna in the control conditions with $v \approx 0$ represented a reproduction efficiency of 1 . The reproduction efficiency for the Daphnia magna exposed to $\mathrm{MeHg}(v>0)$ was calculated as the fraction of the number of neonates produced in the exposed conditions compared to the control conditions. We obtained parameter value $\beta_{2}=10.13$ $\mathrm{mg} \mathrm{C} / \mu \mathrm{g}$ toxicant. Figure B.8 shows the experimental data from Biesinger et al (1982) and the reproduction efficiency function (B.4) with the fitted parameter value.

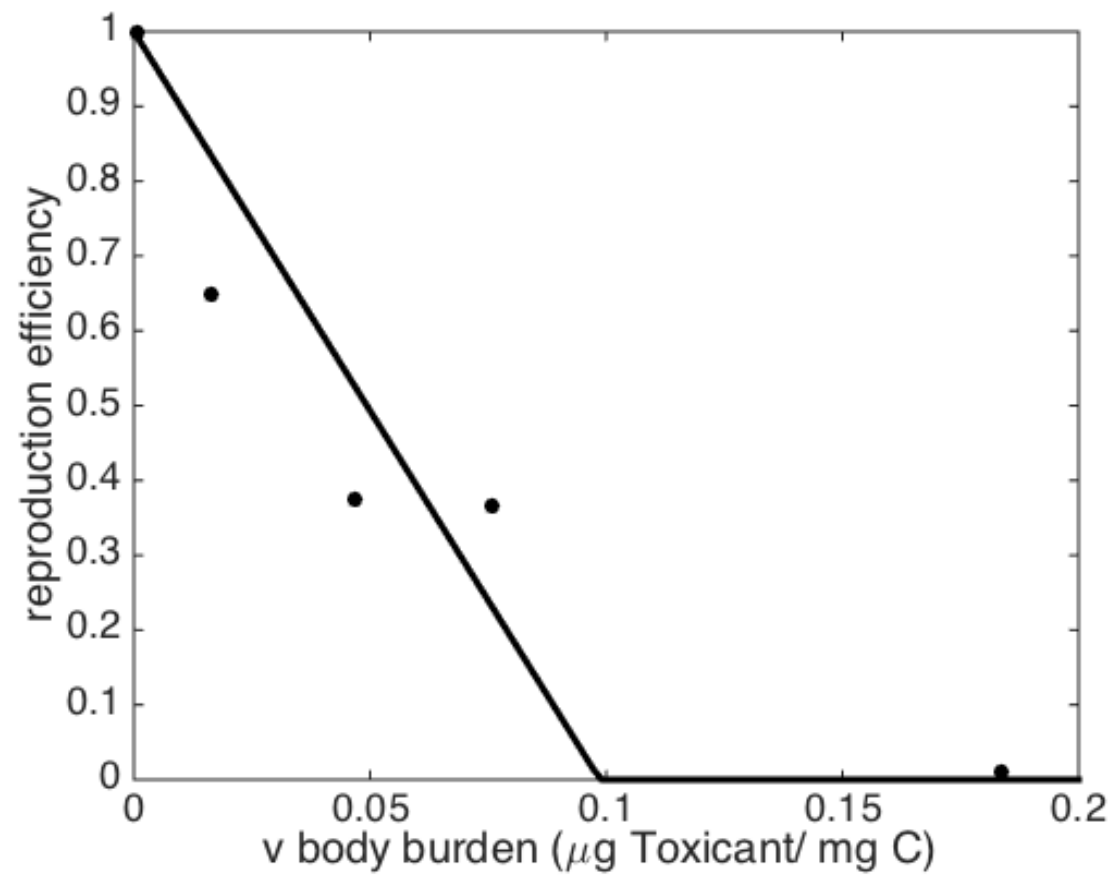

Figure B.8: Experimental data from Biesinger et al (1982) of Daphnia magna exposed to MeHg for 21 days and the reprodcution efficiency function (B.4) with the obtained parameter values using MATLAB's LSQCURVEFIT to fit the data. 


\section{Appendix C. Algae toxicant-inhibited growth data}

\begin{tabular}{|l|c|l|}
\hline Algae & $T_{0}(\mathrm{mg} / \mathrm{L})$ & Source \\
\hline Chlamydomonas reinhardi & 2 & Ben-Bassat et al (1972) \\
Chlorella vulgaris & 0.037 & de Jong and Roman (1965) \\
Chlorella pyrenoidosa & 1 & Hannan and Patouillet (1972) \\
Fragilaria crotonensis & 1 & Tompkins and Blinn (1976) \\
\hline
\end{tabular}

Table C.2: Relevant data from Vocke (1978) compilation of growth responses reported for freshwater algae exposed to mercury. $T_{0}$ is the reported threshold mercury concentrations that resulted in $100 \%$ growth inhibition for the various algal species. This data was used to estimate parameter $\alpha_{2}$ using equation (B.1).

\section{Appendix D. Proof of Theorem 4.1}

Proof. First we show the solutions remain in the rectangle $\mathbf{R}$ defined by $[0, \mathbf{k}] \times\left[0, \frac{P}{\theta}\right]$, then we show solutions are also bounded by the inequality $q x+\theta y<P$. Let $S(t)=(x(t), y(t))$ be a solution of System (11) with $S(0) \in \mathbf{R}$. Assume there exists a time $t_{1}>0$ such that $S\left(t_{1}\right)$ touches or crosses a boundary of $\mathbf{R}$ for the first time. The following cases prove solutions remain in $\mathbf{R}$ by contradiction. Case 1: $x\left(t_{1}\right)=0$

Let $\bar{y}=\max _{t \in\left[0, t_{1}\right]} y(t)<\frac{P}{\theta}$. Then for every $t \in\left[0, t_{1}\right]$,

$$
\begin{aligned}
\frac{d x}{d t} & =\left(\max \left\{0,1-\frac{T}{\sigma_{1}^{2}}\right\}\left(1-\frac{x}{\min \left\{K, \frac{P-\theta y}{q}\right\}}\right)-\frac{y}{a+x}\right) x \\
& \geq\left(\max \left\{0,1-\frac{T}{\sigma_{1}^{2}}\right\}\left(1-\frac{x}{\min \left\{K, \frac{P-\theta \bar{y}}{q}\right\}}\right)-\frac{\bar{y}}{a+x}\right) x \\
& \geq\left(\max \left\{0,1-\frac{T}{\sigma_{1}^{2}}\right\}\left(1-\frac{x}{\min \left\{K, \frac{P-\theta \bar{y}}{q}\right\}}\right)-\frac{\bar{y}}{a}\right) x \\
& \equiv \alpha x
\end{aligned}
$$

This implies that $x\left(t_{1}\right) \geq x(0) e^{\alpha t_{1}}>0$, where $\alpha$ is a constant. This contradicts $x\left(t_{1}\right)=0$ and proves that $S\left(t_{1}\right)$ does not reach this boundary.

Case 2: $x\left(t_{1}\right)=\mathbf{k}=\min \left\{K, \frac{P}{q}\right\}$

Then for every $t \in\left[0, t_{1}\right]$,

$$
\begin{aligned}
\frac{d x}{d t} & =\left(\max \left\{0,1-\frac{T}{\sigma_{1}^{2}}\right\}\left(1-\frac{x}{\min \left\{K, \frac{P-\theta y}{q}\right\}}\right)-\frac{y}{a+x}\right) x \\
& \leq \max \left\{0,1-\frac{T}{\sigma_{1}^{2}}\right\}\left(1-\frac{x}{\min \left\{K, \frac{P}{q}\right\}}\right) x \\
& \leq\left(1-\frac{x}{\mathbf{k}}\right) x
\end{aligned}
$$


Then $x(t)<\mathbf{k}$ by a standard comparison argument. This contradicts $x\left(t_{1}\right)=\mathbf{k}$ and proves that the trajectory does not cross this boundary.

Case 3: $y\left(t_{1}\right)=0$

Then for every $t \in\left[0, t_{1}\right]$,

$$
\begin{aligned}
\frac{d y}{d t} & =\min \left\{\beta_{1}, \frac{Q}{\theta}\right\} \max \left\{0,1-\frac{T}{\sigma_{2}}\left(\gamma+\frac{\beta_{2}}{\sigma_{1}^{2}} \frac{x}{a+x}\right)\right\} \frac{x y}{a+x}-\left(\frac{h_{2} T}{\sigma_{2}}\left(\gamma+\frac{\beta_{2}}{\sigma_{1}^{2}} \frac{x}{a+x}\right)+m_{2}\right) y \\
& \geq-\left(\frac{h_{2} T}{\sigma_{2}}\left(\gamma+\frac{\beta_{2}}{\sigma_{1}^{2}} \frac{x}{a+x}\right)+m_{2}\right) y \\
& \geq-\left(\frac{h_{2} T}{\sigma_{2}}\left(\gamma+\frac{\beta_{2}}{\sigma_{1}^{2}}\right)+m_{2}\right) y \\
& \equiv \alpha y
\end{aligned}
$$

This implies that $y\left(t_{1}\right) \geq y(0) e^{\alpha t_{1}}>0$, where $\alpha$ is a constant. This contradicts $y\left(t_{1}\right)=0$ and proves that $S\left(t_{1}\right)$ does not reach this boundary.

Case 4: $y\left(t_{1}\right)=\frac{P}{\theta}$

Then for every $t \in\left[0, t_{1}\right]$,

$$
\begin{aligned}
\frac{d y}{d t} & =\min \left\{\beta_{1}, \frac{Q}{\theta}\right\} \max \left\{0,1-\frac{T}{\sigma_{2}}\left(\gamma+\frac{\beta_{2}}{\sigma_{1}^{2}} \frac{x}{a+x}\right)\right\} \frac{x y}{a+x}-\left(\frac{h_{2} T}{\sigma_{2}}\left(\gamma+\frac{\beta_{2}}{\sigma_{1}^{2}} \frac{x}{a+x}\right)+m_{2}\right) y \\
& \leq \min \left\{\beta_{1}, \frac{Q}{\theta}\right\} \max \left\{0,1-\frac{T}{\sigma_{2}}\left(\gamma+\frac{\beta_{2}}{\sigma_{1}^{2}} \frac{x}{a+x}\right)\right\} \frac{x y}{a+x} \\
& \leq \frac{Q}{\theta} \max \left\{0,1-\frac{T}{\sigma_{2}}\left(\gamma+\frac{\beta_{2}}{\sigma_{1}^{2}} \frac{x}{a+x}\right)\right\} \frac{x y}{a+x} \\
& \leq \frac{Q}{\theta} \frac{x y}{a+x} \\
& \leq \frac{Q}{\theta} y=\left(\frac{P-\theta y}{\theta x}\right) y=\frac{x P}{\theta}\left(1-\frac{y}{P / \theta}\right) y \\
& \leq \mathbf{k} \frac{P}{\theta}\left(1-\frac{y}{P / \theta}\right) y
\end{aligned}
$$

Then $y(t)<\frac{P}{\theta}$ by a standard comparison argument. This contradicts $y\left(t_{1}\right)=\frac{P}{\theta}$ and proves that the trajectory does not cross this boundary. The above cases prove the trajectories are bounded in $\mathbf{R}$. Now assume $S(0) \in \Omega$ and there exists a time $t_{1}>0$ such that $S\left(t_{1}\right)$ touches or crosses a boundary of $\Omega$ for the first time. The final case proves solutions remain in $\Omega$ by contradiction.

Case 5: $q x\left(t_{1}\right)+\theta y\left(t_{1}\right)=P$

Then $q x\left(t_{1}\right)+\theta y\left(t_{1}\right)<P$ for every $t \in\left[0, t_{1}\right)$ and $q x^{\prime}\left(t_{1}\right)+\theta y^{\prime}\left(t_{1}\right) \geq 0$

$$
\begin{aligned}
x^{\prime}\left(t_{1}\right) & =\max \left\{0,1-\frac{T}{\sigma_{1}^{2}}\right\}\left(1-\frac{x\left(t_{1}\right)}{\min \left\{K, \frac{P-\theta y\left(t_{1}\right)}{q}\right\}}\right) x\left(t_{1}\right)-\frac{x\left(t_{1}\right) y\left(t_{1}\right)}{a+x\left(t_{1}\right)} \\
& \leq \max \left\{0,1-\frac{T}{\sigma_{1}^{2}}\right\}\left(1-\frac{x\left(t_{1}\right)}{\frac{P-\theta y\left(t_{1}\right)}{q}}\right) x\left(t_{1}\right)-\frac{x\left(t_{1}\right) y\left(t_{1}\right)}{a+x\left(t_{1}\right)} \\
& =-\frac{x\left(t_{1}\right) y\left(t_{1}\right)}{a+x\left(t_{1}\right)}
\end{aligned}
$$


and

$$
\begin{aligned}
y^{\prime}\left(t_{1}\right)= & \min \left\{\beta_{1}, \frac{Q\left(t_{1}\right)}{\theta}\right\} \max \left\{0,1-\frac{T}{\sigma_{2}}\left(\gamma+\frac{\beta_{2}}{\sigma_{1}^{2}} \frac{x\left(t_{1}\right)}{a+x\left(t_{1}\right)}\right)\right\} \frac{x\left(t_{1}\right) y\left(t_{1}\right)}{a+x\left(t_{1}\right)} \\
& -\left(\frac{h_{2} T}{\sigma_{2}}\left(\gamma+\frac{\beta_{2}}{\sigma_{1}^{2}} \frac{x\left(t_{1}\right)}{a+x\left(t_{1}\right)}\right)+m_{2}\right) y\left(t_{1}\right) \\
\leq & \frac{Q\left(t_{1}\right)}{\theta} \frac{x\left(t_{1}\right) y\left(t_{1}\right)}{a+x\left(t_{1}\right)} \\
= & \frac{P-\theta y\left(t_{1}\right)}{\theta x\left(t_{1}\right)} \frac{x\left(t_{1}\right) y\left(t_{1}\right)}{a+x\left(t_{1}\right)} \\
= & \frac{q x\left(t_{1}\right)}{\theta} \frac{y\left(t_{1}\right)}{a+x\left(t_{1}\right)}
\end{aligned}
$$

Then $q x^{\prime}\left(t_{1}\right)+\theta y^{\prime}\left(t_{1}\right) \leq q\left(-\frac{x\left(t_{1}\right) y\left(t_{1}\right)}{a+x\left(t_{1}\right)}\right)+\theta\left(\frac{q x\left(t_{1}\right)}{\theta} \frac{y\left(t_{1}\right)}{a+x\left(t_{1}\right)}\right)=0$, a contradiction.

\section{Appendix E. Proof of Theorem 4.2}

Proof. The local stability of $E_{0}=(0,0)$ is determined by the Jacobian in the following form,

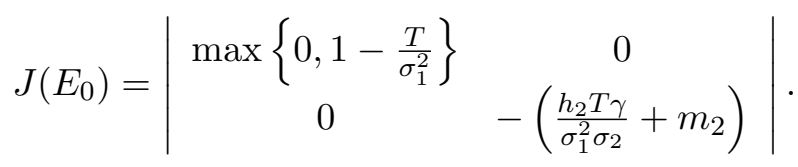

The eigenvalues have different signs, thus $E_{0}$ is a saddle point. The local stability of $E_{1}=(\mathbf{k}, 0)$ is determined by the Jacobian in the following form,

$$
\begin{aligned}
& J\left(E_{1}\right)=\left|\begin{array}{cc}
F(\mathbf{k}, 0)+\mathbf{k} F_{x}(\mathbf{k}, 0) & \left.\mathbf{k} F_{y}(\mathbf{k}, 0)\right) \\
0 & G(\mathbf{k}, 0)
\end{array}\right|
\end{aligned}
$$

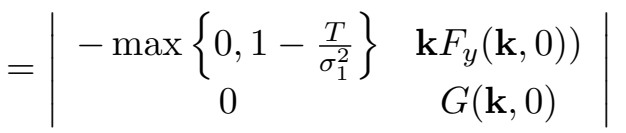

The local stability of $E_{1}$ depends on the sign of $G(\mathbf{k}, 0)$. If $G(\mathbf{k}, 0)$ is positive, then $E_{1}$ is an unstable saddle. If $G(\mathbf{k}, 0)$ is negative, then $E_{1}$ is a locally asymptotically stable node.

\section{References}

Alexander AC, Luis AT, Culp JM, Baird DJ, Cessna AJ (2013) Can nutrients mask community responses to insecticide mixtures? Ecotoxicology 22(7):1085-1100

Andersen T (1997) Pelagic Nutrient Cycles: Herbivores as Sources and Sinks. NY: Springer-Verlag

Andersen T, Elser JJ, Hessen DO (2004) Stoichiometry and population dynamics. Ecology Letters $7(9): 884-900$

Ankley GT, Erickson RJ, Phipps GL, Mattson VR, Kosian PA, Sheedy BR, Cox JS (1995) Effects of light intensity on the phototoxicity of fluoranthene to a benthic macroinvertebrate. Environmental science \& technology 29(11):2828-2833 
Ashauer R, Brown CD (2008) Toxicodynamic assumptions in ecotoxicological hazard models. Environmental Toxicology and Chemistry 27(8):1817-1821

Ashauer R, Boxall AB, Brown CD (2007) New ecotoxicological model to simulate survival of aquatic invertebrates after exposure to fluctuating and sequential pulses of pesticides. Environmental science \& technology 41(4):1480-1486

Ben-Bassat D, Shelef G, Gruner N, Shuval HI (1972) Growth of chlamydomonas in a medium containing mercury

Biesinger KE, Anderson LE, Eaton JG (1982) Chronic effects of inorganic and organic mercury on daphnia magna: Toxicity, accumulation, and loss. Archives of environmental contamination and toxicology 11(6):769-774

Bontje D, Kooi B, Liebig M, Kooijman S (2009) Modelling long-term ecotoxicological effects on an algal population under dynamic nutrient stress. water research 43(13):3292-3300

Danger M, Maunoury-Danger F (2013) Ecological stoichiometry. In: Encyclopedia of Aquatic Ecotoxicology, Springer, pp 317-326

Diehl S (2007) Paradoxes of enrichment: effects of increased light versus nutrient supply on pelagic producer-grazer systems. The American Naturalist 169(6):E173-E191

Elser JJ, Urabe J (1999) The stoichiometry of consumer-driven nutrient recycling: theory, observations, and consequences. Ecology 80(3):735-751

Elser JJ, Dobberfuhl DR, MacKay NA, Schampel JH (1996) Organism size, life history, and n: P stoichiometry. BioScience 46(9):674-684

Elser JJ, Fagan WF, Denno RF, Dobberfuhl DR, Folarin A, Huberty A, Interlandi S, Kilham SS, McCauley E, Schulz KL, et al (2000) Nutritional constraints in terrestrial and freshwater food webs. Nature 408(6812):578-580

Elser JJ, Hayakawa K, Urabe J (2001) Nutrient limitation reduces food quality for zooplankton: Daphnia response to seston phosphorus enrichment. Ecology 82:898-903

Grover JP (2004) Predation, competition, and nutrient recycling: a stoichiometric approach with multiple nutrients. Journal of theoretical biology 229(1):31-43

Hall SR (2004) Stoichiometrically explicit competition between grazers: species replacement, coexistence, and priority effects along resource supply gradients. The American Naturalist 164(2):157-172

Hall SR (2009) Stoichiometrically explicit food webs: feedbacks between resource supply, elemental constraints, and species diversity. Annual Review of Ecology, Evolution, and Systematics 40:503528

Hallam T, De Luna J (1984) Effects of toxicants on populations: A qualitative: Approach iii. environmental and food chain pathways. Journal of Theoretical Biology 109(3):411-429

Hannan PJ, Patouillet C (1972) Effect of mercury on algal growth rates. Biotechnology and Bioengineering 14(1):93-101

Hansen LK, Frost PC, Larson JH, Metcalfe CD (2008) Poor elemental food quality reduces the toxicity of fluoxetine on daphnia magna. Aquatic toxicology 86(1):99-103 
Hessen DO, Elser JJ, Sterner RW, Urabe J (2013) Ecological stoichiometry: An elementary approach using basic principles. Limnol Oceanogr 58(6):2219-2236

Hill WR, Larsen IL (2005) Growth dilution of metals in microalgal biofilms. Environmental science \& technology 39(6):1513-1518

Huang Q, Parshotam L, Wang H, Bampfylde C, Lewis MA (2013) A model for the impact of contaminants on fish population dynamics. Journal of theoretical biology 334:71-79

Huang Q, Wang H, Lewis M (2014) Development of a toxin-mediated predator-prey model applicable to aquatic environments in the athabasca oil sands region. osrin report no. Tech. rep., TR-59. 59 pp. http://hdl. handle. net/10402/era. 40140

Huang Q, Wang H, Lewis MA (2015) The impact of environmental toxins on predator-prey dynamics. Journal of theoretical biology 378:12-30

Ieromina O, Peijnenburg WJ, de Snoo G, Müller J, Knepper TP, Vijver MG (2014) Impact of imidacloprid on daphnia magna under different food quality regimes. Environmental Toxicology and Chemistry 33(3):621-631

de Jong LdD, Roman W (1965) Tolerance ofchlorella vulgaris for metallic and non-metallic ions. Antonie van Leeuwenhoek 31(1):301-313

Karimi R, Chen CY, Pickhardt PC, Fisher NS, Folt CL (2007) Stoichiometric controls of mercury dilution by growth. Proceedings of the National Academy of Sciences 104(18):7477-7482

Kooijman S, Bedaux J (1996) Analysis of toxicity tests on daphnia survival and reproduction. Water Research 30(7):1711-1723

Lessard CR, Frost PC (2012) Phosphorus nutrition alters herbicide toxicity on Daphnia magna. Science of the Total Environment 421:124-128

Li X, Wang H, Kuang Y (2011) Global analysis of a stoichiometric producer-grazer model with holling type functional responses. Journal of mathematical biology 63(5):901-932

Loladze I, Kuang Y, Elser J (2000) Stoichiometry in producer-grazer systems: Linking energy flow with element cycling. Bull Math Biol 62:1137-1162

Mackay D, Puig H, McCarty L (1992) An equation describing the time course and variability in uptake and toxicity of narcotic chemicals to fish. Environmental toxicology and chemistry 11(7):941-951

McCauley E, Nelson WA, Nisbet RM (2008) Small-amplitude cycles emerge from stage-structured interactions in daphnia-algal systems. Nature 455(7217):1240-1243

Mergler D, Anderson HA, Chan LHM, Mahaffey KR, Murray M, Sakamoto M, Stern AH (2007) Methylmercury exposure and health effects in humans: a worldwide concern. AMBIO: A Journal of the Human Environment 36(1):3-11

Miller FJ, Schlosser PM, Janszen DB (2000) Habers rule: a special case in a family of curves relating concentration and duration of exposure to a fixed level of response for a given endpoint. Toxicology 149(1):21-34 
Peace A (2015) Effects of light, nutrients, and food chain length on trophic efficiencies in simple stoichiometric aquatic food chain models. Ecological Modelling 312:125-135

Peace A, Zhao Y, Loladze I, Elser JJ, Kuang Y (2013) A stoichiometric producer-grazer model incorporating the effects of excess food-nutrient content on consumer dynamics. Math Biosci 244(2):107-115

Peace A, Wang H, Kuang Y (2014) Dynamics of a producer-grazer model incorporating the effects of excess food nutrient content on grazers growth. Bulletin of mathematical biology 76(9):2175-2197

Pieters BJ, Jager T, Kraak MH, Admiraal W (2006) Modeling responses of daphnia magna to pesticide pulse exposure under varying food conditions: intrinsic versus apparent sensitivity. Ecotoxicology 15(7):601-608

Rosenzweig ML, et al (1971) Paradox of enrichment: destabilization of exploitation ecosystems in ecological time. Science 171(3969):385-387

Sarwar N, Malhi SS, Zia MH, Naeem A, Bibi S, Farid G, et al (2010) Role of mineral nutrition in minimizing cadmium accumulation by plants. Journal of the Science of Food and Agriculture 90(6):925-937

Sterner RW, Elser JJ (2002) Ecological stoichiometry: the biology of elements from molecules to the biosphere. Princeton University Press

Tompkins T, Blinn DW (1976) The effect of mercury on the growth rate of fragilaria crotonensis kitton and asterionella formosa hass. Hydrobiologia 49(2):111-116

Tsui MT, Wang WX (2004) Uptake and elimination routes of inorganic mercury and methylmercury in daphnia magna. Environmental science \& technology 38(3):808-816

Tsui MT, Wang WX (2006) Acute toxicity of mercury to daphnia magna under different conditions. Environmental science \& technology 40(12):4025-4030

Urabe J, Sterner RW (1996) Regulation of herbivore growth by the balance of light and nutrients. Proc Nat Acad Sci 93(16):8465-8469

Urabe J, Elser JJ, Kyle M, Yoshida T, Sekino T, Kawabata Z (2002) Herbivorous animals can mitigate unfavourable ratios of energy and material supplies by enhancing nutrient recycling. Ecology Letters 5(2):177-185

Van Voorn GA, Kooi BW, Boer MP (2010) Ecological consequences of global bifurcations in some food chain models. Mathematical biosciences 226(2):120-133

Vocke RW (1978) Growth responses of selected freshwater algae to trace elements and scrubber ash slurry generated by coal-fired power plants. Retrospective Theses and Dissertations Paper 6523

Walker CH, Sibly R, Hopkin S, Peakall DB (2012) Principles of ecotoxicology. CRC Press

Wang H, Kuang Y, Loladze I (2008a) Dynamics of a mechanistically derived stoichiometric producergrazer model. Journal of Biological Dynamics 2(3):286-296

Wang H, Sterner RW, Elser JJ (2012) On the strict homeostasis assumption in ecological stoichiometry. Ecological Modelling 243:81-88 
Wang L, Zhou Q, Ding L, Sun Y (2008b) Effect of cadmium toxicity on nitrogen metabolism in leaves of solanum nigrum 1 . as a newly found cadmium hyperaccumulator. Journal of hazardous materials 154(1):818-825

Wang WX (2012) Biodynamic understanding of mercury accumulation in marine and freshwater fish. Advances in Environmental Research 1(1):15-35

Wang WX, Rainbow PS (2008) Comparative approaches to understand metal bioaccumulation in aquatic animals. Comparative Biochemistry and Physiology Part C: Toxicology \& Pharmacology $148(4): 315-323$

Wang WX, Fisher N, Luoma S (1996) Kinetic determinations of trace element bioaccumulation in the mussel mytilus edulis. Oceanographic Literature Review 3(44):273

Xie T, Yang X, Li X, Wang H (2016) Complete global and bifurcation analysis of a stoichiometric predator-prey model. Submitted

Xing W, Huang W, Liu G (2010) Effect of excess iron and copper on physiology of aquatic plant spirodela polyrrhiza (1.) schleid. Environmental toxicology 25(2):103-112 